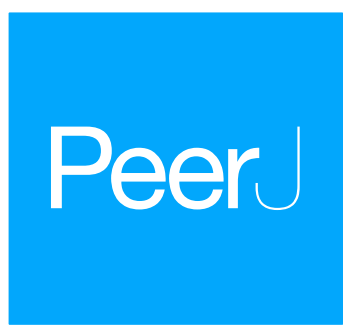

\title{
Adaptive genetic variation at three loci in South African vervet monkeys (Chlorocebus pygerythrus) and the role of selection within primates
}

\author{
Willem G. Coetzer ${ }^{1}$, Trudy R. Turner ${ }^{2}$, Christopher A. Schmitt ${ }^{3}$ and \\ J. Paul Grobler ${ }^{1}$ \\ ${ }^{1}$ Department of Genetics, University of the Free State, Bloemfontein, South Africa \\ ${ }^{2}$ Department of Anthropology, University of Wisconsin-Milwaukee, Milwaukee, WI, USA \\ ${ }^{3}$ Department of Anthropology, Boston University, Boston, MA, USA
}

\section{ABSTRACT}

Vervet monkeys (Chlorocebus pygerythrus) are one of the most widely distributed non-human primate species found in South Africa. They occur across all the South African provinces, inhabiting a large variety of habitats. These habitats vary sufficiently that it can be assumed that various factors such as pathogen diversity could influence populations in different ways. In turn, these factors could lead to varied levels of selection at specific fitness linked loci. The Toll-like receptor (TLR) gene family, which play an integral role in vertebrate innate immunity, is a group of fitness linked loci which has been the focus of much research. In this study, we assessed the level of genetic variation at partial sequences of two TLR loci (TLR4 and 7) and a reproductively linked gene, acrosin (ACR), across the different habitat types within the vervet monkey distribution range. Gene variation and selection estimates were also made among 11-21 primate species. Low levels of genetic variation for all three gene regions were observed within vervet monkeys, with only two polymorphic sites identified for TLR4, three sites for TLR7 and one site for ACR. $T L R 7$ variation was positively correlated with high mean annual rainfall, which was

Submitted 23 February 2018

Accepted 22 May 2018

Published 4 June 2018

Corresponding author

Willem G. Coetzer,

coetzerwg@ufs.ac.za

Academic editor

Kara Hoover

Additional Information and

Declarations can be found on page 19

DOI 10.7717/peerj.4953

(C) Copyright

2018 Coetzer et al.

Distributed under

Creative Commons CC-BY 4.0

OPEN ACCESS linked to increased pathogen abundance. The observed genetic variation at TLR4 might have been influenced by numerous factors including pathogens and climatic conditions. The ACR exonic regions showed no variation in vervet monkeys, which could point to the occurrence of a selective sweep. The TLR4 and TLR7 results for the among primate analyses was mostly in line with previous studies, indicating a higher rate of evolution for TLR4. Within primates, ACR coding regions also showed signs of positive selection, which was congruent with previous reports on mammals. Important additional information to the already existing vervet monkey knowledge base was gained from this study, which can guide future research projects on this highly researched taxon as well as help conservation agencies with future management planning involving possible translocations of this species.

Subjects Anthropology, Biodiversity, Biogeography, Genetics

Keywords Pathogen diversity, Environmental factors, Adaptive variation, Vervet monkey 


\section{INTRODUCTION}

Data on the level of genetic adaptation within animal populations is an important aspect of conservation biology. Population or habitat specific adaptations should be considered when studying animal population dynamics and evolution, as these aspects of population genetic diversity will undoubtedly provide important information to guide conservation management (Funk et al., 2012). Neutral genetic variation has long been the marker of choice but can overestimate the amount of genetic diversity within a population and therefore overestimate a population's viability. The consideration of both adaptively linked and neutral markers during population level studies is therefore important (Funk et al., 2012; Hartmann, Schaefer \& Segelbacher, 2014).

Vervet monkeys (Chlorocebus pygerythrus) are one of the most widely distributed nonhuman primate species found in South Africa, with only Papio ursinus found in a wider range (Hoffmann \& Hilton-Taylor, 2008). This species occurs across all the South African provinces, inhabiting a large variety of habitats (Skinner \& Chimimba, 2005; Kingdon et al., 2008), including xeric and mesic zones. These primates are listed as 'Least concern' in the Red list of mammals of South Africa, Swaziland and Lesotho (Turner et al., 2016a). The genus Chlorocebus is a taxon of significant scientific interest within research areas such as immunodeficiency virus pathology (Ma et al., 2013), parasite ecology (Gaetano et al., 2014; Wren et al., 2015; Chapman et al., 2016), neuroscience (Woods et al., 2011; Mendell et al., 2014), social learning (Botting et al., 2018) and sexual selection (Borgeaud et al., 2015; Rodríguez et al., 2015), and these studies require a clear understanding of genetic boundaries and connectivity between populations, using both neutral and adaptive markers. Vervet monkeys also often find their way to primate rehabilitation centres following human primate conflicts (Wimberger, Downs \& Boyes, 2010) and reintroduction of these animals to suitable recipient populations without considering the provenance of the rehabilitated animals should be discouraged. A recent study focusing on South African vervet monkey phylogeography identified mtDNA structuring among populations linked to current and past habitat distributions, geographic barriers, distance and female philopatry (Turner et al., 2016b). Three broad genetic clusters were identified, corresponding to (i) the northern part of the distribution range, including the northern part of the Indian Ocean coastal belt, (ii) the central regions of South Africa and

(iii) the southern part of the Indian Ocean coastal belt and adjacent inland areas. Turner et al. (2016b) urged that the addition of nuclear loci should be considered in future research to provide a better understanding of the influence of selection on the observed genetic structuring seen among South African vervet monkey populations. A genome wide study by Svardal et al. (2017) showed that viruses played an important role during Chlorocebus evolution, which is in line with the findings of Enard et al. (2016) who identified viruses as the main driver of evolutionary adaptation in mammals. Strong signals for selection were specifically identified for genes involved in cell signalling and transcriptional regulation following viral exposure in Chlorocebus monkeys (Svardal et al., 2017). Further research into the adaptive genetic diversity of vervet monkeys will not only be of value for future studies on this widely researched taxon but can also provide 
conservation authorities with the needed information to make informed decisions with regards to possible translocations.

The different habitats within the vervet distribution range differ sufficiently that it can be assumed that different environmental factors could drive adaptation in local populations. This could then lead to selection at specific fitness linked loci. In recent years, there has been an increasing trend to use adaptive variation in population and phylogenetic analyses (Vasemägi \& Primmer, 2005; Gatesy \& Swanson, 2007; Ayoub et al., 2009; Gonzalez-Quevedo et al., 2015; Quéméré et al., 2015). Fitness-linked genes are influenced by external elements such as host-pathogen interactions (Vasemägi \& Primmer, 2005; Holderegger, Kamm \& Gugerli, 2006), which directly affect population fitness. The study of variation at adaptive loci can therefore provide valuable information on interaction between environment, genotype and the selective influences that shape patterns of diversity.

Pathogen-mediated selection is widely accepted as an important evolutionary driver in nature (Little, 2002). In this regard, the Toll-like receptor (TLR) gene family, which play an integral role in vertebrate innate immunity, is a group of fitness linked loci which has been the focus of much phylogeographic and phylogenetic research (Wlasiuk \& Nachman, 2010; Tschirren et al., 2012; Hartmann, Schaefer \& Segelbacher, 2014). TLRs respond to a wide range of pathogen-associated molecular patterns (PAMPs) (exogenous and endogenous, Roach et al., 2005); for example, lipoteichoic acids (gram-positive bacteria, Takeuchi et al., 1999), lipopolysaccharides (gram-negative bacteria, Poltorak et al., 2000), CpG DNA (bacterial, Hemmi et al., 2000; viral, Lund et al., 2003) and single-stranded RNA (viral, Diebold et al., 2004; Lund et al., 2004) to name a few. There are generally two classes of TLRs; one recognising mainly extracellular threats such as lipopolysaccharides and expressed on the outer cell membrane, and the other being expressed within intracellular organelles and recognising mainly intracellular threats such as CpG DNA (Takeda, Kaisho \& Akira, 2003; Roach et al., 2005; Vinkler \& Albrecht, 2009; Fornůsková et al., 2013).

Two TLR genes were selected for this study on the basis of the PAMPs associated with each. First, TLR4 was selected due to its responds to a range of PAMPs including lipopolysaccharide from gram-negative bacteria as well as the fusion protein of respiratory syncytial virus (Kurt-Jones et al., 2000), whereas TLR7 was selected due to its involved in immune responses to viral ssRNA (Diebold et al., 2004; Lund et al., 2004) and phagosomal bacteria (Mancuso et al., 2009). These two TLR genes covers a wide range of possible pathogen-mediated responses. Gram-negative bacteria can cause various infections, from pathogenic Escherichia coli causing gastrointestinal infections (Manning, 2010) to Klebsiella pneumoniae causing pneumonia (Aujla et al., 2008; Twenhafel et al., 2008) and Neisseria meningitidis being a causal agent of meningococcal meningitis (Brandtzaeg, 2006).

Non-human primates are also affected by numerous viral pathogens. African green monkey simian immunodeficiency virus (SIVagm) is a ssRNA lentivirus (Kaup et al., 2005) associated with primates from the genus Chlorocebus. These viruses do, however, not cause AIDS symptoms in their host species and is therefore studied at length to identify the reasons for this lack of symptoms (Ma et al., 2013). Other ssRNA viruses 
related to Chlorocebus species include simian hepatitis A virus (Balayan, 1992), influenza (Webster et al., 1992) and a range of simian arteriviruses and simian pegiviruses (Bailey et al., 2014a, 2014b, 2016). Using these two genes would therefore provide valuable information with regards to vervet monkey adaptations to viral and bacterial pathogens.

The use of a reproductively linked gene can provide additional information with regards to local adaptations among populations, especially long separated populations. The acrosin $(A C R)$ gene encodes for the serine proteinase $A C R$, which is linked to fertility in animals and thought to be involved in secondary binding of the sperm cell to the egg zona pellucida leading to proteolysis of the extracellular egg coat (Keime, Adham \& Engel, 1990; Gatesy \& Swanson, 2007). Reports indicated that this gene show significant signs of adaptive change within mammals (Swanson et al., 2001), making it a good candidate for the assessment of the influences of population isolation within a species.

Here, we assessed the level of genetic variation at partial sequences of one reproductively-linked gene (ACR) and two immune-linked loci (TLR4 and TLR7) across eight habitat types within the vervet monkey distribution range, to complement the work by Turner et al. (2016b) using a neutral mtDNA locus. We also investigated the effect of natural selection on the evolution of these gene segments within a wider sample of primates. This study will add substantially to our current knowledge of vervet monkey evolution in South Africa, which could aid future research projects as well as conservation management plans.

\section{METHODS}

\section{Ethics}

Sampling approval and research ethical clearance was obtained for a previous study using mtDNA analysis (Turner et al., 2016b) from the Institutional Care and Use Committee of the University of Wisconsin-Milwaukee (Ref no. 07-08 \#32) and the Inter-Faculty Animal Ethics Committee of the University of the Free State, South Africa (Ref no. UFSAED13/2010). All samples from this study were sourced from the Turner et al. (2016b) study and no new additional samples were included.

\section{Samples and DNA extraction}

Samples from a total of 81 vervet monkeys were included in this study (Table S1), representing nine localities from across the distribution range (Turner et al., 2016b), located in five biomes (Nama-Karoo, Savanna, Grassland, Albany thicket and Indian Ocean coastal belt biomes; Table 1; Fig. 1A) and eight bioregions/vegetation types. These localities represent significantly different environmental conditions, based on parameters such as the mean annual precipitation (MAP), mean annual ambient temperature (MAT) and maximum annual temperature (MaxT) (Table 1). Due to the philopatric nature of vervet monkey troops, there is expected to be a certain level of relatedness among members of the same troop. We therefore aimed to select specimens from multiple troops, if possible. All samples were sourced from the Department of Genetics, University of the Free State, Biobank and were previously collected by Turner et al. (2016b). All DNA extracts were obtained from ear biopsies. DNA extraction was performed using the Roche 


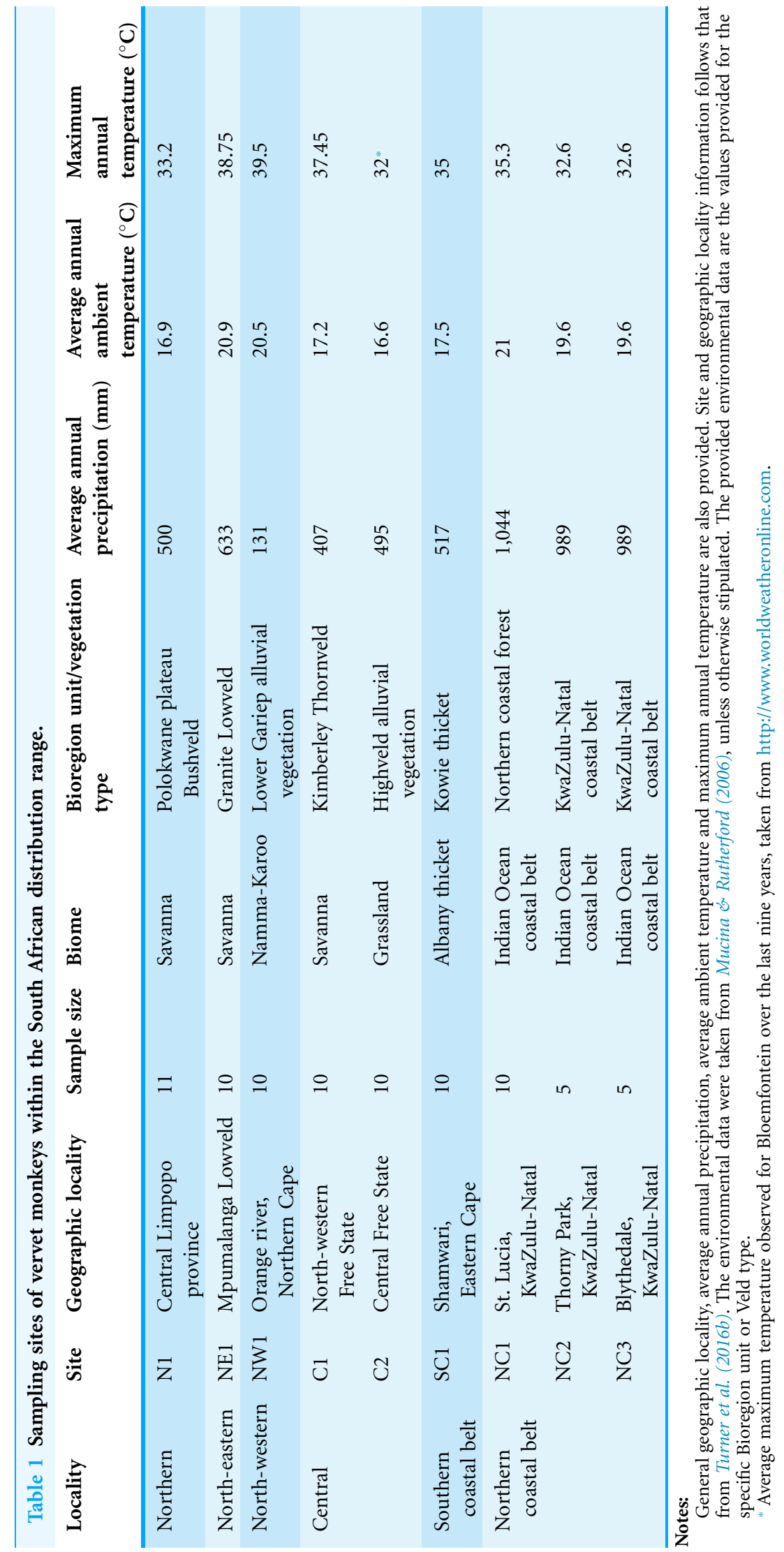


(A)

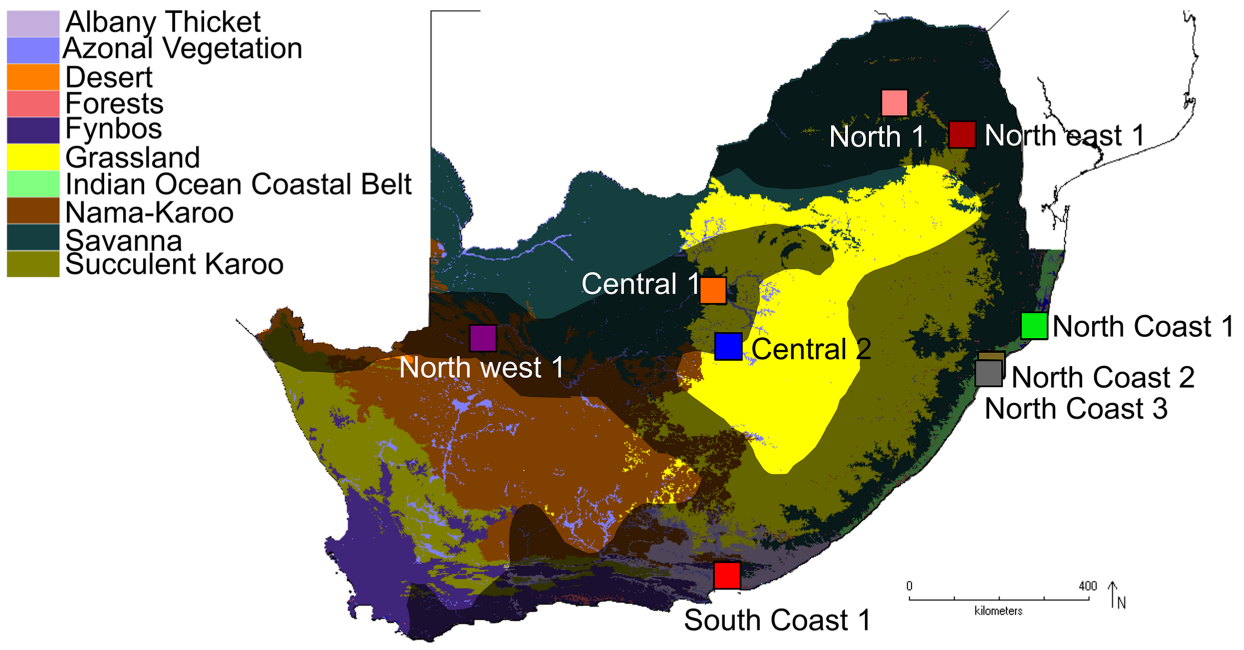

(B)

(C)
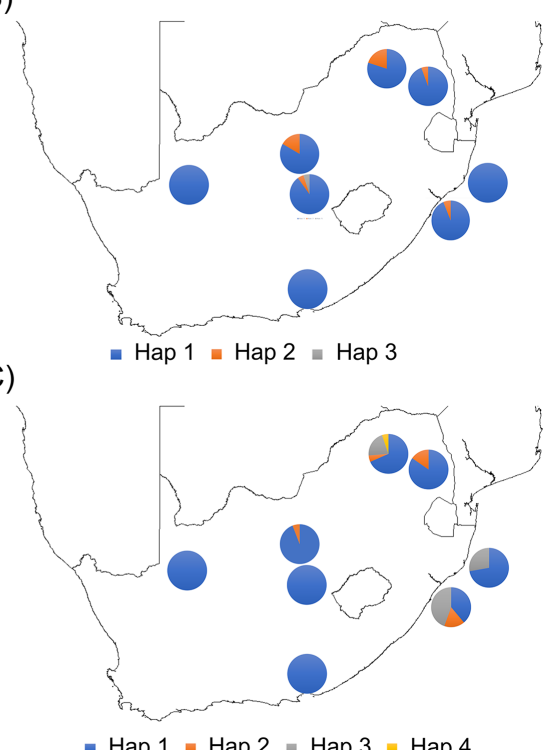

Figure 1 South African maps providing sampling locality information and haplotype frequencies for the two TLR loci. (A) Biome map indicating vervet monkey sampling localities across different biomes. The vervet monkey distribution range is indicated by the grey shading. The software DIVA-GIS (http://www.diva-gis.org/) was used to create the vervet distribution range and biome map, which is based on information obtained from Hoffmann \& Hilton-Taylor (2008) and Mucina \& Rutherford (2006). (B) Vervet TLR4 haplotype frequencies per locality and (C) vervet TLR7 haplotype frequencies per locality.

High Pure polymerase chain reaction (PCR) Template Preparation Kit (Roche Diagnostics, Indianapolis, IN, USA). Sample preparation included a re-hydration step, followed by the manufacturer's instructions. The initial digestion step was carried out overnight. All DNA samples were stored at $-20^{\circ} \mathrm{C}$.

\section{DNA amplification and sequencing}

Primers for amplification of partial segments from the ACR, TLR4 and TLR7 genes were designed using Primer3 (Rozen \& Skaletsky, 1999) as implemented in Geneious v9 software (Kearse et al., 2012). Primers were designed using the online GenBank genome sequences for Chlorocebus sabaeus (ACR, Chromosome 19: NC_023660; TLR4, Chromosome 12: NC_023653; TLR7, Chromosome X: NC_023671.1). See Table 2 for the primer sequences and annealing temperature information. The ACR amplicons covered a partial segment of exon 4 and the complete intron 4 (Chl_ACR2) and complete exon 5 (Chl_ACR1), totalling a $\sim 1,000$ bp sequence. This region was selected because it was reported that exon 5 is the most rapidly evolving segment of the mammalian ACR gene (Gatesy \& Swanson, 2007). The ACR intronic region was a by-product from sequencing the ACR exon 4 and exon 5 regions. The TLR 4 primers covered a partial $\sim 700$ bp segment of exon 3, with the TLR7 primers amplifying a partial $\sim 1,350$ bp segment of exon 3 . The first $\sim 700 \mathrm{bp}$ of the TLR4 exon 3 gene was selected as it is the largest of the three TLR4 exons observed in primates and it contains the extracellular leucine-rich repeat domain, which is responsible for ligand recognition (Janssens \& Beyaert, 2003). The TLR7 
Table 2 Primer sequences and annealing temperatures for the three gene regions amplified in this study.

\begin{tabular}{lllcc} 
Primer & Forward sequence $\left(5^{\prime}-\mathbf{3}^{\prime}\right)$ & Reverse sequence $\left(5^{\prime}-\mathbf{3}^{\prime}\right)$ & KAPA HiFi Ta & Ampliqon TEMPase Ta \\
\hline Chl_ACR1 & CAGCAGGAAACCATGTGACT & TTTTCTCAGCACTGAAGGGC & - & $64{ }^{\circ} \mathrm{C}$ \\
Chl_ACR2 & TATGCTGATGGAGGCACGTGTGGA & GCGCCTTTCTTGCTGTCTTTGCAC & - & $64{ }^{\circ} \mathrm{C}$ \\
Chl_TLR4 & ACAGAAGCTGGTGGCTGTGG & TTGAAAGCAACTCTGGTGTG & $66{ }^{\circ} \mathrm{C}$ & $64{ }^{\circ} \mathrm{C}$ \\
Chl_TLR7a & ACCATGTGATCGTGGACTGC & GGGGCACATGCTGAAGAGAG & $66{ }^{\circ} \mathrm{C}$ & $64{ }^{\circ} \mathrm{C}$ \\
Chl_TLR7b & TGCCCCATTTCCTTGTACGC & AAGCCGGTTGTTGGAGAAGTC & $62{ }^{\circ} \mathrm{C}$ & $64{ }^{\circ} \mathrm{C}$ \\
\hline
\end{tabular}

Note:

The ACR primer pair was only amplified with the Ampliqon TEMPase Hot Start 2x Master Mix. All primer sequences are provided in 5' to 3' direction.

protein is mainly encoded by the third exon of this gene (Astakhova et al., 2009). The region targeted in our study covers approximately a third of the $5^{\prime}$ end of exon 3, which also contains the extracellular domain. Two PCR kits (KAPA HiFi HotStart ReadyMix PCR kit; KAPA Biosystems, Cape Town, South Africa and Ampliqon TEMPase Hot Start 2x Master Mix, Odense, Denmark) were used, due to product availability. The manufacturer protocols were followed for both kits. The annealing temperatures $\left(T_{a}\right)$ for the different gene segments are provided in Table 2.

Amplification success was assessed on a 1\% Agarose gel. PCR amplicons were purified using the BioSpin PCR Purification Kit (BioFlux, Tokyo, Japan). The ABI PRISM ${ }^{\circledR}$ BigDye $^{\circledR}$ Terminator v3.1 Cycle Sequencing Kit (Applied Biosystems Division, Foster City, CA, USA) was used for all sequencing reactions. Sequences were analysed with an ABI 3130 Genetic Analyzer, following sequence product clean-up with the ZR DNA Sequencing Clean-up ${ }^{\mathrm{TM}}$ Kit (Zymo Research, Irvine, CA, USA).

\section{Sequence diversity within vervet monkeys}

All raw sequences were assembled and edited using Geneious. Sequence alignments for each gene region were performed with ClustalW (Thompson, Higgins \& Gibson, 1994) as implemented in Geneious. Diploid genotypes were resolved into haplotypes using the Bayesian method in Phase v2.1 (Stephens, Smith \& Donnelly, 2001; Stephens \& Scheet, 2005) implemented in DnaSP v5.10.01 (Librado \& Rozas, 2009). TLR7 is located on the $\mathrm{X}$ chromosome, and we therefore only performed haplotype inference analysis for the sequences from females, as only one gene copy is present in males. The hemizygous male sequences were then added to the phased female sequences for downstream analyses. The number of iterations were set to 50,000, with a burn-in of 5,000, and with all other settings at default values. Samples were grouped according to eight sampling regions for all analyses. Data from NC2 and NC3 were combined due to small sample sizes, the close proximity between sites and similar environmental conditions observed between these sites (Table 1). Summary statistics performed with DnaSP included the number of polymorphic sites $(S)$, number of non-synonymous sites, number of haplotypes (h), haplotype diversity $(\mathrm{Hd})$ and nucleotide diversity $(\pi$, rounded to four decimal places due to small magnitude). The program PopArt (Leigh \& Bryant, 2015) was used to assess the relationship between haplotypes by generating a minimum spanning network of each gene region. 
Protein homology modelling was used to provide a clearer perspective of the position of each partial sequence used in the current study. The partial sequences were translated to amino acid sequences using Geneious software. Homology modelling was then performed in SWISS-MODEL (Biasini et al., 2014), and the partial protein structures were superimposed on reference protein structures using DeepView/Swiss-PdbViewer (Guex \& Peitsch, 1997; http://www.expasy.org/spdbv/). No complete Chlorocebus ACR mRNA or amino acid sequences were available for comparison. We therefore used SWISS-MODEL to identify the best fit template for model building. An ACR protein structure for Ovis aries beta-acrosin (PDB ID: 1fiw; Tranter et al., 2000) was identified as the best fit. Our vervet partial $A C R$ sequence was then superimposed onto this structure using DeepView/Swiss-PdbViewer (Guex \& Peitsch, 1997; http://www.expasy.org/spdbv/).

A Chlorocebus TLR4 protein structure was modelled for use as a reference structure using a Chlorocebus sabaeus amino acid sequence downloaded from the Uniprot Knowledgebase (UniProtKB accession: A0A0D9RL22), with a published human TLR4 protein reference structure (PDB ID: 4G8G; Ohto et al., 2012). The partial sequences generated from our study was then modelled according to, and then superimposed onto, this Chlorocebus sabaeus TLR4 protein structure. A reference protein structure for Chlorocebus TLR7 was constructed using a Chlorocebus sabaeus amino acid sequence from the Uniprot Knowledgebase (UniProtKB accession: A0A0D9SDT9) and a Macaca mulatta protein structure as a reference (PDB ID: 5gmf; Zhang et al., 2016). Our partial Chlorocebus pygerythrus TLR7 sequences were then superimposed on this Chlorocebus sabaeus scaffold.

A Mantel test was performed in Arlequin v3.5 (Excoffier \& Lischer, 2010) to estimate the correlation between geographic distance and the observed genetic diversity. The pairwise $F_{\mathrm{ST}}$ values generated in Arlequin were used as measure of genetic distance, with the geographic distance calculated using an online tool for latitude/longitude to geographic distance conversions (Veness, 2017). The correlation between the estimated Hd against each of three environmental factors, MAP, MAT and MaxT, were assessed via generalized linear model (GLM) analysis, using PAST v3 software (Hammer, Harper \& Ryan, 2001). The environmental data were taken from Mucina \& Rutherford (2006), which is the most widely used and complete vegetation and biome data for South Africa. A GLM analysis was used as our Hd data did not conforming to normality. PAST implements the basic version of the GLM, and a least squares linear regression was utilised due to its robustness. Correlation analyses using $\mathrm{Hd}$ values calculated from only the nonsynonymous sites were also performed. A correlation analysis was also conducted using the Hd values for the mitochondrial D-loop region assessed by Turner et al. (2016b) and the MAP, MAT and MaxT values for the corresponding regions assessed in the current study. This assessment was done to compare neutral genetic variation patterns to that observed from adaptive markers.

\section{Assessment of natural selection within South African vervet monkeys}

The TLR 4 and TLR7 sequence alignments for the South African vervet monkeys were used to assess the influence of natural selection on these gene fragments within the South 
African populations. The ACR locus was excluded from the selection analyses within vervets due to lack of variation in both exons.

To estimate the presence of positive and/or negative selection, two codon-based methods as implemented in the Datamonkey web server were used (Kosakovsky Pond \& Frost, 2005). The methods included the MEME method for identifying sites under episodic diversifying or positive selection via a maximum likelihood approach (Murrell et al., 2012), and the Bayesian FUBAR model described by Murrell et al. (2013) which is a superior model to the related likelihood-based FEL model. Rather than reporting evidence of positive selection using $p$-values, FUBAR uses posterior probabilities due to the Bayesian algorithm used. FUBAR is also capable of analysing large alignments at a high speed, and might outperform FEL if positive selection is present but weak (Murrell et al., 2013; HyPhy, 2018). Datamonkey ignores identical sequences and therefore only calculate selection from the phased haplotype data. Sites were accepted as candidates for selection with $p$-values $<0.1$ for MEME and posterior probability (Post Pr) $>0.9$ for FUBAR. The optimal model of nucleotide substitution was selected for each dataset using the Akaike information criterion (Akaike, 1974) in jModelTest (Darriba et al., 2012), prior to the site-by-site selection analyses in Datamonkey. Default settings were used for all other parameters.

An additional selection analysis was conducted in Codeml (Kohlhase, 2006), as implemented in PamlX v1.3.1 (Yang, 2007; Xu \& Yang, 2013), using the model pair M7 and M8 to assess site-by-site selection for the three primate sequence alignments. The codon is considered the unit of evolution (Goldman \& Yang, 1994) in these models and use the non-synonymous/synonymous rate ration $\left(\omega=\mathrm{d}_{\mathrm{N}} / \mathrm{d}_{\mathrm{S}}\right)$ for selection analysis. It was shown that the likelihood-ration tests (LRT) for this model pair identified sites of positive selection more readily than the alternative M1 and M2 pair. This was attributed to the unrealistic nature of the strict neutral model (M1) which does not account for sites with $0<\omega<1$ (Yang et al., 2000). The F3×4 model of codon frequencies were used in all analyses. A NJ tree obtained from Datamonkey for each gene was used as a working topology. These models were compared for each gene region using a LRT calculated in the program Impact_S (Maldonado et al., 2014). A Bayes empirical Bayes approach (Yang, Wong \& Nielsen, 2005) was used to identify codons under selection for model M8. Sites with a posterior probability of $>90 \%$ were considered as candidates for selection, as identifying specific sites under selection is more difficult than to identify a specific proportion of sites (Wlasiuk \& Nachman, 2010).

\section{Assessment of natural selection within primates}

A second set of analyses focused on the ACR, TLR4 and TLR7 sequence alignments of 23 primate taxa and the South African vervet haplotypes from this study. Primate sequences for $A C R$ and both TLR coding regions were downloaded from GenBank. Sequences from 21 primate species were downloaded for TLR4 and TLR7. Only 11 GenBank sequences covered our amplified $A C R$ coding region. The exonic regions for the ACR sequences were identified via the Chlorocebus sabaeus (NC_023660) ACR gene region viewed through the graphical viewer tool from GenBank. See Table S2 for details on 
sequence accession numbers. The ACR, TLR4 and TLR7 vervet monkey haplotype were added to the GenBank sequences. Sequence alignments were performed using the online version of MAFFT (Katoh et al., 2002; Katoh, Rozewicki \& Yamada, 2017), which is more accurate when analysing datasets containing insertions or deletions (Golubchik et al., 2007).

The same Datamonkey and Codeml selection models used in the vervet monkey analyses were implemented to identify sites under selection in the primate dataset. Identical assessment methods were also implemented when considering candidate sites.

\section{RESULTS}

\section{Genetic diversity within vervet monkey populations}

More than $90 \%$ of all vervet monkey samples successfully amplified at the three gene regions. Following trimming of the aligned sequences, a total of 585 bp of TLR4 (partial exon 3), 1,296 bp of TLR7 (partial exon 3) and 1034 bp of ACR (partial exon 4, intron 4 and partial exon 5) were available for downstream analyses. All haplotypes were deposited on GenBank (Accession numbers: ACR, MG014710-MG014711; TLR4, MG014712MG014714; TLR7, MG014715-MG014719). A moderate amount of genetic diversity was observed for the two TLR exonic gene regions, with only one polymorphic site observed within the intronic region of the vervet $A C R$ gene region (SNP frequencies: $\mathrm{T} / \mathrm{T}=0.76 ; \mathrm{T} / \mathrm{G}=0.2 ; \mathrm{G} / \mathrm{G}=0.04)$. No polymorphisms were observed in either amplified $A C R$ exonic region. For the TLR gene regions we observed two polymorphic sites for $T L R 4$, with one non-synonymous position identified in the vervet population from the $\mathrm{C} 2$ region, and three polymorphic sites for TLR7, with one non-synonymous position observed in vervet populations from the $\mathrm{N} 1, \mathrm{NC} 1$ and $\mathrm{NC} 2 \& 3$ regions. Contrasting patterns of Hd was observed for the two TLR genes (Table 3). The highest TLR4 haplotype diversities were estimated for the northern $(\mathrm{N} 1, \mathrm{Hd}=0.337)$ and central $(\mathrm{C} 1, \mathrm{Hd}=0.294)$ regions, with the highest TLR7 values observed for the northern and northern coastal belt regions $(\mathrm{N} 1, \mathrm{Hd}=0.509$; $\mathrm{NC} 1, \mathrm{Hd}=0.425 ; \mathrm{NC} 2 \& 3$, Hd =0.660; Fig. 2). Similar patterns were observed for the nucleotide diversity estimates. ACR Hd estimates followed a similar pattern to TLR4 diversity, with the highest levels seen in the northern and central regions $(\mathrm{N} 1, \mathrm{Hd}=0.519 ; \mathrm{C} 2, \mathrm{Hd}=0.337)$ and the dominant haplotype occurring at a frequency of 0.86 . One dominant haplotype was observed for both TLR4 (92.47\%) and TLR7 (80.77\%) across all populations (Figs. 1B and 1C; Fig. 3). The partial ACR, TLR4 and TLR7 sequences generated for this study were modelled onto protein models to view the position of these segments and the identified non-synonymous mutations in TLR4 and TLR7 (Fig. 4). Both non-synonymous mutations resulted in amino acid changes in loops on the protein structure close to ligand recognition sites (Figs. 4B and 4C).

No significant correlation was found between Hd and geographic distance between vervet monkey sampling localities, following the Mantel analyses $(A C R, r=-0.006$, $p=>0.05$; TLR4, $r=0.197, p>0.05$; TLR7, $r=0.208, p>0.05)$. The GLM analysis identified a negative, although non-significant, correlation between TLR4 Hd and MAP (Slope $=-0.0002 ; p>0.05 ;$ Fig. 5) and TLR4 Hd and MAT (Slope $=-0.004 ; p>0.5$ ), with 
Table 3 Genetic diversity estimates for TLR4 and TLR7 at the eight sampling regions for South African vervet monkeys.

\begin{tabular}{|c|c|c|c|c|c|c|c|}
\hline Gene & Population & $N$ & Size (bp) & $\begin{array}{l}\text { Polymorphic } \\
\text { sites }(S)\end{array}$ & $\begin{array}{l}\text { Number of } \\
\text { haplotypes (h) }\end{array}$ & $\begin{array}{l}\text { Haplotype } \\
\text { diversity (Hd) }\end{array}$ & $\begin{array}{l}\text { Nucleotide } \\
\text { diversity }(\pi)\end{array}$ \\
\hline \multirow[t]{10}{*}{ TLR4 } & All primates & 24 & 585 & 245 & 23 & 0.996 & 0.0838 \\
\hline & All vervet & 73 & 585 & 2 & 3 & 0.141 & 0.0002 \\
\hline & N1 & 10 & & 1 & 2 & 0.337 & 0.0006 \\
\hline & NE1 & 9 & & 1 & 2 & 0.111 & 0.0002 \\
\hline & $\mathrm{C} 1$ & 9 & & 1 & 2 & 0.294 & 0.0005 \\
\hline & $\mathrm{C} 2$ & 10 & & 2 & 3 & 0.195 & 0.0003 \\
\hline & NW1 & 9 & & 0 & 1 & 0.000 & 0.0000 \\
\hline & SC1 & 10 & & 0 & 1 & 0.000 & 0.0000 \\
\hline & $\mathrm{NC1}$ & 8 & & 0 & 1 & 0.000 & 0.0000 \\
\hline & NC2\&3 & 8 & & 1 & 2 & 0.125 & 0.0002 \\
\hline \multirow[t]{10}{*}{$T L R 7$} & All primates & 26 & 1,299 & 361 & 23 & 0.988 & 0.0496 \\
\hline & All vervet & 80 & 1,296 & 3 & 4 & 0.330 & 0.0004 \\
\hline & N1 & 11 & & 3 & 4 & 0.509 & 0.0007 \\
\hline & NE1 & 9 & & 1 & 2 & 0.282 & 0.0002 \\
\hline & $\mathrm{C} 1$ & 10 & & 1 & 2 & 0.118 & 0.0001 \\
\hline & $\mathrm{C} 2$ & 10 & & 0 & 1 & 0.000 & 0.0000 \\
\hline & NW1 & 10 & & 0 & 1 & 0.000 & 0.0000 \\
\hline & SC1 & 10 & & 0 & 1 & 0.000 & 0.0000 \\
\hline & NC1 & 10 & & 2 & 2 & 0.425 & 0.0007 \\
\hline & NC2\&3 & 10 & & 3 & 3 & 0.660 & 0.0010 \\
\hline \multirow[t]{10}{*}{$A C R$} & All primates $\$$ & 12 & 615 & 176 & 11 & 0.985 & 0.1075 \\
\hline & All vervet & 75 & 1,034 & 1 & 2 & 0.242 & 0.0002 \\
\hline & $\mathrm{N} 1^{*}$ & 11 & & 1 & 2 & 0.519 & 0.0005 \\
\hline & $\mathrm{NE} 1^{*}$ & 9 & & 0 & 1 & 0.000 & 0.0000 \\
\hline & $\mathrm{C} 1^{*}$ & 9 & & 1 & 2 & 0.294 & 0.0003 \\
\hline & $\mathrm{C} 2 *$ & 10 & & 1 & 2 & 0.337 & 0.0003 \\
\hline & NW1* & 8 & & 0 & 1 & 0.000 & 0.0000 \\
\hline & $\mathrm{SC} 1 *$ & 9 & & 1 & 2 & 0.209 & 0.0002 \\
\hline & $\mathrm{NC}^{*}$ & 10 & & 0 & 1 & 0.000 & 0.0000 \\
\hline & NC2\& $3 *$ & 9 & & 1 & 2 & 0.209 & 0.0002 \\
\hline
\end{tabular}

Notes:

$\mathrm{N}$, Number of samples; bp, sequence size in base pairs, S, number of polymorphic sites; h, number of haplotypes, Hd, haplotype diversity; $\pi$, nucleotide diversity estimates are provided.

* Diversity estimates were calculated from the complete amplified fragment. The single polymorphic site for the ACR region was observed in the intronic segment of the sequence.

$\$$ Diversity estimates only determined for the partial exon 4 and exon 5 regions.

a positive correlation to MaxT (Slope $=0.014 ; p>0.05$ ). For TLR7 a positive correlation was observed between Hd and MAP (Slope $=0.001 ; p<0.05$; Fig. 5). A positive and a negative, although non-significant, correlation was observed for MAT and MaxT respectively (MAT; Slope $=0.053 ; p>0.05$; MaxT; Slope $=-0.031 ; p>0.05$ ). The same trends were observed with the GLM analyses based on the non-synonymous TLR Hd estimates. No significant correlations were observed between the neutral D-Loop region 


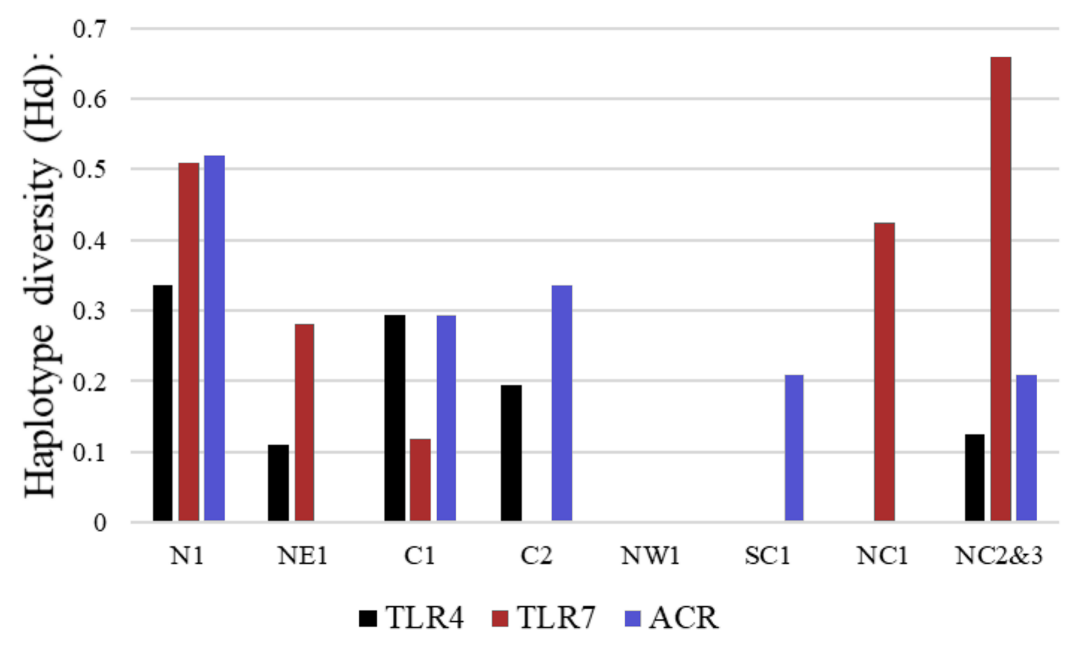

Figure 2 Haplotype diversity estimates for the different vervet monkey sampling localities as calculated in DnaSP. The black bars represent values calculated for TLR4, red bars TLR7 and blue bars ACR haplotype diversity values. Full-size $\boldsymbol{\oplus}$ DOI: 10.7717 /peerj.4953/fig-2

and MAP (Slope $=-317.24, p>0.05)$ and MAT (Slope $=1.867, p>0.05)$. A significantly positive correlation was, however, identified between D-loop Hd and MaxT (Slope = 0.093, $p<0.05)$. See Table S3 for full GLM statistics.

\section{Role of selection within vervet monkeys}

For the vervet TLR4 alignment, only one codon was identified by the FUBAR method as possibly being under negative (purifying) selection, which is a non-synonymous mutation at codon 144 (human codon 359; nucleotide 432, T -> C). A strong indication of negative selection at one TLR7 codon (codon 419, human codon 500, nucleotide 432, C -> T) was identified with FUBAR (Table S4). This polymorphism is, however, a synonymous mutation and the non-synonymous mutation at TLR7 codon 402 (human codon 483) was not identified as a candidate for selection. These codon positions are based on our amplified fragments lengths. No codons under positive selection were identified.

\section{Genetic diversity within primates}

All three primate sequence alignments showed high levels of genetic diversity, with 176, 245 and 361 polymorphic sites observed for ACR, TLR4 and TLR7 respectively (Table 3). The highest number of polymorphic sites were observed for TLR7, and the highest Hd levels were observed for TLR4 $(\mathrm{Hd}=0.996$; Table 3$)$.

\section{Role of selection within primates}

Within primates, eight codons showed signs of positive, and possibly episodic, selection for the ACR coding region following the MEME results. FUBAR only identified one candidate site for positive selection, with M8 identifying two candidate sites. Furthermore, 21 ACR codons were identified as potentially under negative selection. Two and seven sites of potential positive selection were identified for TLR4 using FUBAR and M8 respectively. Twelve candidate sites for episodic positive selection was identified by the MEME analysis. 
(A)

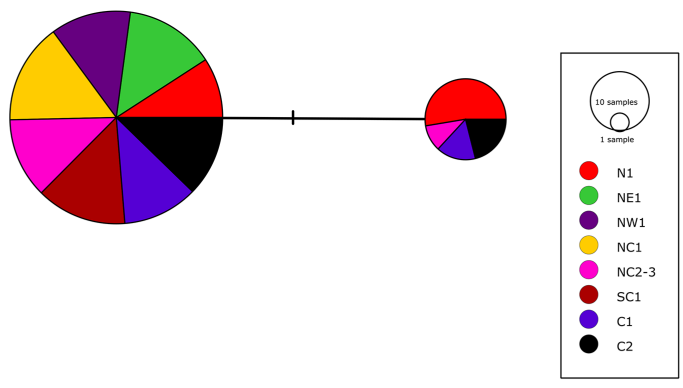

(B)
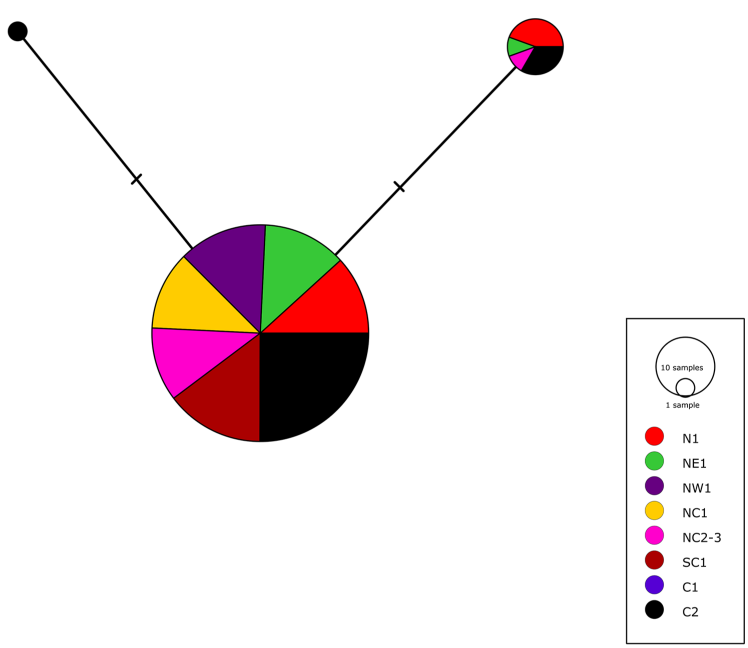

(C)

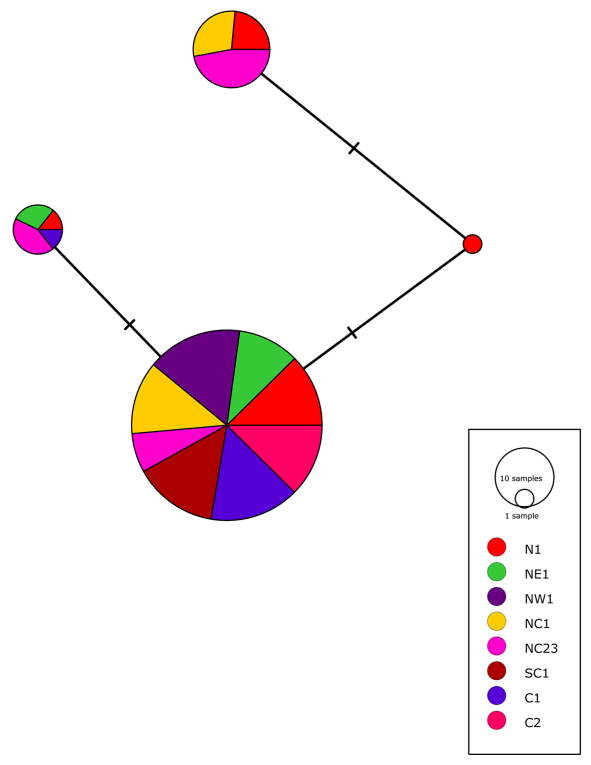

Figure 3 The minimum spanning haplotype networks estimated for the three gene regions sequenced in the current study. (A) Acrosin $(A C R)$ haplotype network calculated from the intronic and two exonic regions amplified, (B) Toll-like receptor (TLR) 4 haplotype network and (C) TLR7 haplotype network. The size of each circle is in relation to the number of sequences analysed.

Full-size DOI: 10.7717/peerj.4953/fig-3 


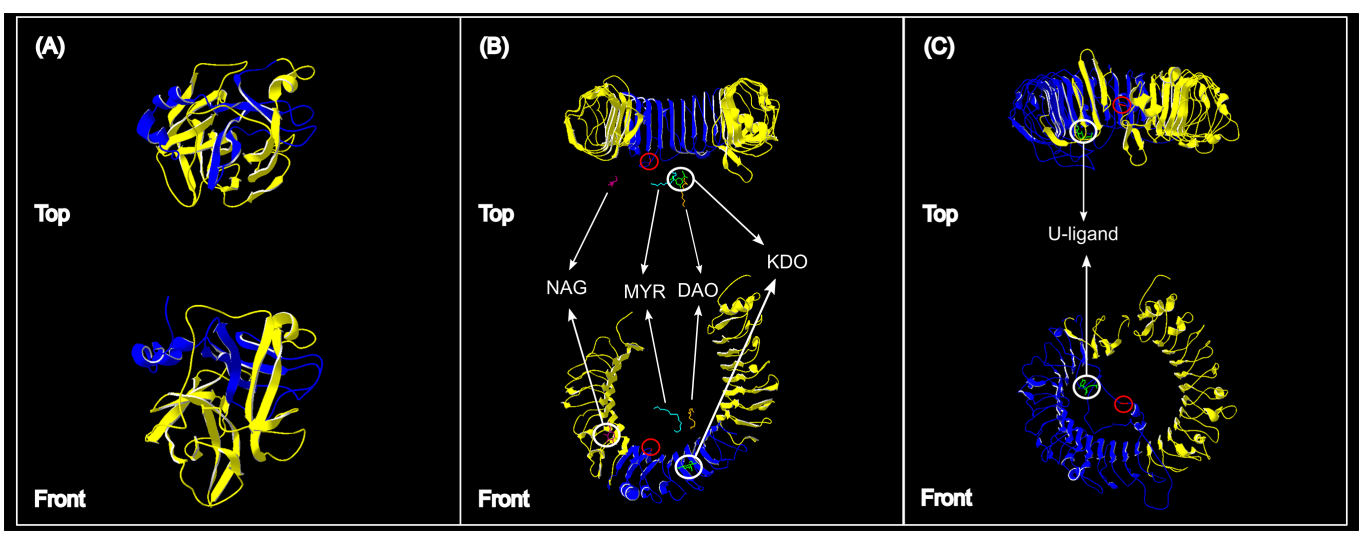

Figure 4 Protein structures of the three genes assessed for genetic variation in South African vervet monkeys. (A) The partial ACR segment (blue) investigated in this study covered $32 \%$ of the reference $\beta$-acrosin protein (yellow). (B) The partial vervet TLR4 segment (blue) covered $31 \%$ of the Chlorocebus sabaeus TLR4 reference protein B-chain. The known ligand structures are shown as: NAG, purple; MYR, turquoise; DAO, orange; KDO, green. (C) The partial vervet TLR7 segment (blue) covered $52 \%$ of the Chlorocebus sabaeus TLR7 reference protein A-chain. The identified U-ligand structure is shown in green. The non-synonymous SNPs are identified by the red circle in B and C.

Full-size

(A)

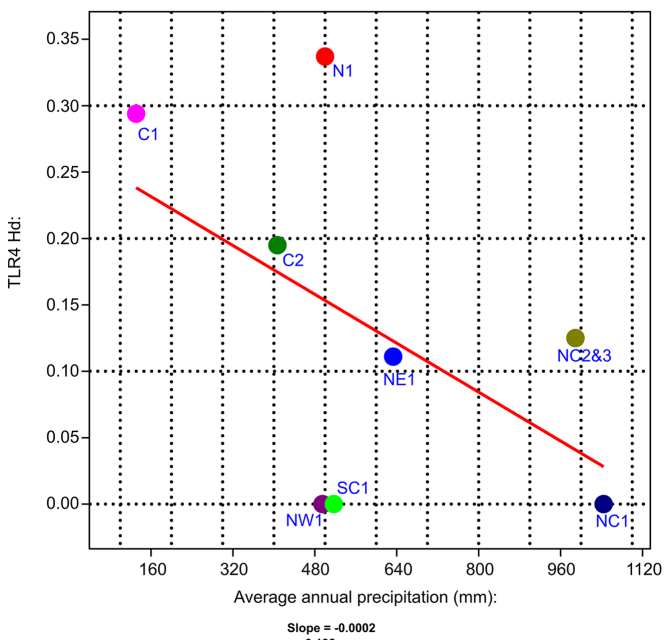

(B)

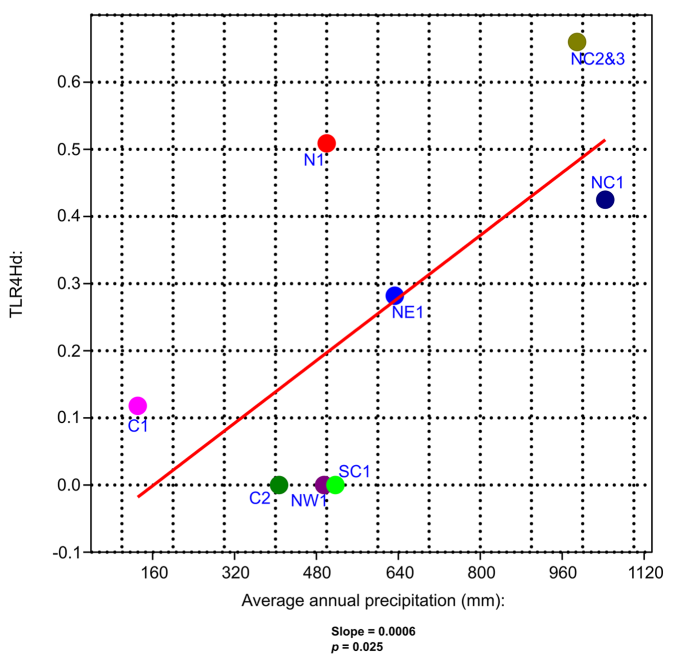

Figure 5 The generalised linear model (GLM) results for the correlation analysis between vervet TLR4 and TLR7 haplotype diversity and mean annual precipitation. (A) Mean annual precipitation (mm) vs TLR4 haplotype diversity (Hd) and (B) mean annual precipitation (mm) vs TLR7 Hd. N1, Northern; NE1, North eastern; NW1, North western; C1, Central 1; C2, Central 2; NC1, Northern coastal belt 1; NC2, Northern coastal belt 2; NC3, Northern coastal belt 3; SC1, Southern coastal belt 1 . Full-size iص DOI: 10.7717 /peerj.4953/fig-5

Five sites of possible negative selection were identified for TLR4 following the FUBAR analysis (Table S4). Between the two immune-linked genes, TLR7 displayed the highest amount of candidate sites for positive selection $(n=6)$ identified with FUBAR, but only three sites were identified with M8. Ten sites possibly under episodic positive selection was identified with MEME, with 52 candidate sites under possible negative selection. 


\section{DISCUSSION}

The genetic diversity estimates for South African vervet monkey immune-linked genes showed significant correlations to environmental factors associated with specific bioregions within South Africa. Host-pathogen interactions can shape the genetic variation observed in host immune-linked genes (Hamilton, 1982; Little, 2002; Zhan et al., 2002; Villaseñor-Cardoso \& Ortega, 2011). Pathogen prevalence and abundance has also been linked to climatic factors such as precipitation and temperature (Guernier, Hochberg \& Guégan, 2004; Harvell et al., 2009; Lafferty, 2009; Dunn et al., 2010).

\section{Vervet monkey variation and selection}

The higher TLR7 diversity observed along the Indian Ocean coastal belt had a strong positive correlation to the high mean rainfall observed in this area. The only nonsynonymous mutation observed in this gene region was also seen in the Indian Ocean coastal belt populations. A number of studies have linked higher rainfall to increased human and non-human primate pathogen prevalence (Kupek, de Sousa \& de Souza, 2000; Guernier, Hochberg \& Guégan, 2004; Chapman et al., 2010; Gaetano et al., 2014). A study on African green monkey SIVagm infections in South African vervet monkeys, showed a distinct geographic structuring of SIVagm genetic strains across South Africa (Ma et al., 2013). Three main clusters were identified; one with only Free State (Grassland biome) strains, one with Eastern Cape (Albany thicket biome) and KwaZulu-Natal (Indian Ocean coastal belt) strains and a third with mostly KwaZulu-Natal strains. According to the Ma et al. (2013) study one can infer that the vervet monkeys from the Indian Ocean coastal belt region are exposed to a wider variety of SIVagm strains. Villaseñor-Cardoso \& Ortega (2011) suggested that a higher level of variation at immunelinked loci in a population could lead to an increased potential for a population to respond to a wider range of pathogen-associated molecules. A higher level of pathogen diversity could therefore support the occurrence of a higher TLR7 gene diversity in this area. It was also observed that the non-synonymous mutation identified in our TLR7 dataset occurs close to a uridine-5'-monophosphate ligand recognition site (Fig. 4C). This site is crucial for TLR7 recognition of viral ssRNAs (Diebold et al., 2006; Zhang et al., 2016) originating from viruses such as SIV (Kaup et al., 2005), HIV-1 (Heil et al., 2004; Simmons et al., 2013), vesicular stomatitis virus (Lund et al., 2004), hepatitis C virus (Lee et al., 2006) and influenza virus (Lund et al., 2004; Wang et al., 2008).

The negative correlation between vervet monkey TLR4 regional genetic variation and the MAP, although insignificant, was interesting. Higher rainfall is generally linked to higher pathogen diversity (Lafferty, 2009), which in turn could lead to higher TLR diversity. Higher TLR4 Hd values were, however, observed in the central regions than seen in the Indian Ocean coastal belt regions and the only non-synonymous mutation was also observed in the central region. A number of possible ligands were observed close to the non-synonymous mutation site identified for the vervet TLR4 sequences (Fig. 4B). All of these ligands are associated with gram negative bacteria. The monosaccharide $\mathrm{N}$-acetyl-D-glucosamine (NAG or GalNAc) forms part of the O-specific polysaccharide of gram-negative bacterial lipopolysaccharides (LPS) (Kilár, Dörnyei \& Kocsis, 2013). NAG is 
also an essential component of fungal cell walls (Lee et al., 2008) as well as some parasites (Araujo, Souto-Padrón \& Souza, 1993) and is excreted by mucolytic bacteria (Sicard et al., 2017). The ulosonic acid 3-deoxy-D-manno-oct-2-ulosonic acid (KDO) is a component of the LPS inner core of most gram negative bacteria (Kilár, Dörnyei \& Kocsis, 2013), as well as the inner core of LPS of enteric gram-negative bacilli like N. meningitidis (Tzeng et al., 2002). The saturated fatty-acids lauric acid (DAO) and Myristic acid (MYR) forms part of the Lipid A component of LPS (Lee et al., 2001; Bäckhed et al., 2003). Lipid A is known as an endotoxin responsible for the pathogenicity of gram negative bacteria (Raetz et al., 1991; Ribeiro, Zhou \& Raetz, 1999; Tzeng et al., 2002).

Bacterial abundance and diversity will vary among the different regions, with some species more prevalent in drier areas than others. Patz et al. (1996) observed that meningococcal meningitis epidemics, in sub-Saharan African human populations, predominantly occur during the hot dry season. This disease is mainly caused by the gram-negative bacteria N. meningitidis (Brandtzaeg, 2006). The highest MaxTs were also notably observed for the central regions (Table 1) and could affect TLR4 diversity in vervet monkeys from this region. Numerous heat shock proteins are associated with TLR4 activity and vice versa (Ohashi et al., 2000; Asea, 2003; Roelofs et al., 2006). Small Heat Shock Protein B8 (HSP22) have been identified as a ligand for TLR4 during inflammation caused by rheumatoid arthritis (Roelofs et al., 2006) and HSP70 is known to have chaperokine activity by interacting with TLR4 following cellular stress such as pathogen exposure or exercise (Asea, 2003). Ohashi et al. (2000) suggested that TLR4's murine ortholog, Tlr4 is a mediator for heat shock protein 60 (HSP60) in mice. Further analysis of different HSP genes could provide more insights to the relationship between heat shock proteins and TLR4 diversity and regional temperature differences across the vervet monkey distribution range. A combination of TLR4 mediation of heat shock proteins and exposure to gram-negative bacteria more prevalent in drier areas could in theory drive the retention of different haplotypes in these areas. Divergence of vervet monkeys from the central region from those in the coastal regions was estimated at 1.099 million years ago (Turner et al., 2016b). Immune genes generally evolve at a faster rate than other genes (Hurst \& Smith, 1999), and therefore the time since divergence would have been sufficient to support the occurrence of the observed haplotype variation between the two regions. The different patterns of genetic diversity observed between TLR4 and TLR7 highlights the intricate role different environmental factors or pathogen types (bacterial vs viral) can play on immune gene evolution. More in-depth sampling and larger sequence lengths, as well as a study on bacterial diversity in vervet monkey populations, might provide a better understanding of TLR4 diversity in these primates and the role these factors might play.

The positive correlation observed between the mitochondrial D-loop and MaxT could be due to the mitochondrial involvement in cell metabolism (Wilson et al., 1985).

Lovegrove (2003) showed that ambient temperature has a strong effect on basal metabolic rate. The correlation of mtDNA D-loop variation and MaxT could thus be due to the role this region plays in replication and expression of mitochondrial genes (Sbisà et al., 1997), such as cytochrome b which is involved in metabolism and forms an important 
component of the mitochondrial electron-transfer chain (Zhang et al., 1998). This result will need to be assessed in further detail, either through sequencing of targeted metabolic genes or through whole mitochondrial genome sequencing of specimens from the study localities. These additional sequencing data will make it possible to better understand the link between climate and mtDNA variation.

Failure to identify signs of positive selection at the two vervet TLR gene segments can be attributed to the low number of haplotypes (TLR4 haplotype $n=3$; TLR7 haplotype $n=5$ ) identified for analysis. The lack of positive selection at TLR genes within species could also be linked to the occurrence of episodic selection (Wlasiuk \& Nachman, 2010). Episodic positive selection is a known consequence of pathogen-mediated selection as pathogen infections might be more sporadic in nature than long established events (Wlasiuk \& Nachman, 2010; Grueber, Wallis \& Jamieson, 2014). Sites under episodic positive selection will mainly be under strong purifying selection during their evolution, with bursts of strong positive selection occurring in some lineages (Murrell et al., 2012). These sites can, however, be masked by the overpowering signal of purifying selection that is at play. The MEME analysis for the detection of episodic selection, however, did not identify any sites under episodic selection. Small sample size could, however, also have affected this analysis.

A number of studies have suggested that diversity at synonymous positions could in fact have adaptive significance and influence protein expression (Chamary, Parmley \& Hurst, 2006; Hunt et al., 2014) by either changing splice sites (Pagani, Raponi \& Baralle, 2005; Parmley, Chamary \& Hurst, 2006; Batista et al., 2017) or mRNA secondary structure (Duan et al., 2003; Chamary \& Hurst, 2005; Chen et al., 2017). The observation of possible purifying selection at a synonymous position at TLR7 further supports this view. We were, however, unable to identify the possible effect these synonymous mutations have on TLR7 expression. This will have to be assessed in further analyses.

The ACR gene show significant levels of variation between mammalian species, with exon 5 being the most rapidly evolving segment (Gatesy \& Swanson, 2007). The mammalian ACR gene is, however, functionally conserved across mammalian species, highlighting its role in mammalian fertility (Raterman \& Springer, 2008). Lack of variation within the amplified vervet $A C R$ fragment and the disproportional occurrence of one gene variant, could be linked to this conservation of functionality within the vervet monkey species. Natural selection would favour sperm which contains a functionally stronger gene variant, which will outperform other variants leading to a selective sweep, resulting in a dominant variant remaining in the species. Metz, Robles-Sikisaka \& Vacquier (1998) suggested that the occurrence of a selective sweep might have led to the observed lack of genetic diversity at the reproductive gene lysin in red abalone species (Haliotis rufescens). Further analysis of gene regions located close to the vervet ACR gene will be required to verify the occurrence of a selective sweep at this gene, as genetic hitchhiking is a known consequence of selective sweeps (Choudhuri, 2014). An assessment of the level of $A C R$ gene differentiation between and within all Chlorocebus species would also be an interesting future study. We only had one ACR sequence from Chlorocebus sabaeus, which showed a $21 \mathrm{bp}$ indel in the proline rich region of exon 5 when compared to our vervet 
ACR sequences. Additional analyses could shed more light on the evolution of this gene within the genus Chlorocebus.

\section{Variation and selection within primates}

The high number of sites under negative selection at TLR7 supports the observation by Nakajima et al. (2008) that TLR7 is subject to negative/purifying selection in Old World primates. Within primates, TLR7 had, overall, the lowest amount of positively selected sites compared to TLR4 which is also congruent with previous findings Wlasiuk \& Nachman (2010). The small difference in number of sites under positive selection between TLR4 and TLR7 in our study can also be attributed to the smaller sequence length of the TLR4 region in our study compared to TLR7. The work by Wlasiuk \& Nachman (2010) focused on the complete coding regions of primate TLR genes and found a larger difference in the number of sites under selection for these two genes. Forniskova et al. (2013) observed a similar trend between rodent Tlr4 $($ Tlr4 polymorphic sites $=545)$ and Tlr7 ( Tlr7 polymorphic sites $=466)$ sequences while assessing the genetic variation and evolutionary processes involved in these two genes and 23 Murinae species. A study assessing the autosomal sequence variation of European and African Bos taurus and Asian Bos indicus indicus revealed that TLR7 showed no genetic variation in any of the breeds, whereas TLR4 showed higher than average signs of genetic variation in Bos indicus (Murray et al., 2010). The higher level of positive selection observed for TLR4 vs $T L R 7$ can be associated with stronger selective pressures playing a role on non-viral TLR loci (TLR4) compared to viral TLRs (TLR7) in primates (Nakajima et al., 2008; Wlasiuk \& Nachman, 2010).

Between species variation for $A C R$ was prominent, with numerous indels observed within the proline rich region of exon 5 . This proline rich region is cleaved during the conversion of the zymogen form proacrosin to the mature form (Adham, Schlösser \& Engel, 2004). A comparison between various artiodactyl ACR exon 5 sequences by Gatesy \& Swanson (2007), however, showed no signs of indels within this region. This could be explained by different evolutionary and life histories of artiodactyls and primates. Different reproductive strategies could be a driver for this difference, with artiodactyls producing small numbers of large, well-developed, offspring capable of escaping predators and primates giving birth to a few large offspring which needs to be carried for protection. This behaviour limits the number of offspring primates can produce per season (Sibly \& Brown, 2009). Sibly \& Brown (2007) also showed that artiodactyls have higher reproductive rates than primates. This was linked to primates occupying areas with lower predation, which is linked to the number of offspring needed for population growth (Sibly \& Brown, 2007). Raterman \& Springer (2008) observed no sites under significant positive selection at $A C R$ for placental mammals. In contrast to the results from Raterman \& Springer (2008), signs of positive selection for ACR in mammals were identified by Swanson, Nielsen \& Yang (2003) supporting the nine sites of possible positive selection identified within our primate $A C R$ dataset.

Signs of strong negative selection was observed in all three genes. Negative or purifying selection is responsible for the removal of deleterious mutations from the genome, and 
thereby preventing the accumulation of these mutations (Fay, Wyckoff \& Wu, 2001). This can be linked to the importance of maintaining stable functional copies of immune-linked and reproductive genes in a population. These strong signals of negative selection can also potentially mask the occurrence of sites under episodic positive selection (Murrell et al., 2012).

\section{CONCLUSION}

Results from the current study confirm that adaptation to some environmental factors (rainfall and pathogen prevalence) can be linked to genetic variation observed at different immune-linked genes. Specifically, vervet TLR diversity could be shaped by environmental drivers linked to pathogen abundance and prevalence. Vervet monkey TLR4 gene diversity might be shaped by gram-negative bacteria linked to drier climates, as well as its involvement in heat shock protein activity. Higher rainfall and possible increased pathogen prevalence in high rainfall areas, were linked to the observed TLR7 gene variation for South African vervet monkeys. These contrasting patterns of gene diversity coincides with the strong genetic structuring previously observed in vervet monkey mtDNA diversity. All three genes (ACR, TLR4 and TLR7) are under strong selective pressures within primates. The clear differences in evolutionary patterns observed between the two TLR genes might best be explained by the location of expression, as well as the different types of pathogens they respond to. The observations from this study add valuable information to the already existing knowledge surrounding South African vervet monkey evolution and could be valuable for future research in biogeography or host-

pathogen ecology. These results will also help to assist conservation agencies to better plan re-introduction or translocation programs for rehabilitated animals, if needed. The genetic structuring linked to selective pressures associated to different environments should therefore be considered when identifying appropriate re-introduction sites or recipient populations.

\section{ACKNOWLEDGEMENTS}

The authors would like to thank all those involved in the original sample collection for the Turner et al. (2016b) study. Specifically, Dr Joseph G. Lorenz and Dr Nelson B. Freimer for their contributions towards the larger vervet monkey project. We would also like to thank Elmarie Blom and Rudi Lombaard for their assistance in the laboratory.

\section{ADDITIONAL INFORMATION AND DECLARATIONS}

\section{Funding}

The study was funded by the University of the Free State Postdoctoral Fellowship Grant. The funders had no role in study design, data collection and analysis, decision to publish, or preparation of the manuscript.

\section{Grant Disclosures}

The following grant information was disclosed by the authors:

University of the Free State Postdoctoral Fellowship Grant. 


\section{Competing Interests}

The authors declare that they have no competing interests.

\section{Author Contributions}

- Willem G. Coetzer conceived and designed the experiments, performed the experiments, analysed the data, contributed reagents/materials/analysis tools, prepared figures and/or tables, authored or reviewed drafts of the paper, approved the final draft.

- Trudy R. Turner contributed reagents/materials/analysis tools, approved the final draft.

- Christopher A. Schmitt approved the final draft, significant contribution to sample and data collection.

- J. Paul Grobler conceived and designed the experiments, contributed reagents/ materials/analysis tools, authored or reviewed drafts of the paper, approved the final draft.

\section{Animal Ethics}

The following information was supplied relating to ethical approvals (i.e. approving body and any reference numbers):

Sampling and research ethical clearance was obtained for the original paper (Turner et al., 2016b) from the Institutional Care and Use Committee of the University of Wisconsin-Milwaukee (Ref no. 07-08 \#32) and the Inter-Faculty Animal Ethics Committee of the University of the Free State, South Africa (Ref no. UFS-AED13/2010). All samples from this study were sourced from the Turner et al. (2016b) study and no new additional samples were included.

\section{DNA Deposition}

The following information was supplied regarding the deposition of DNA sequences:

All sequences generated are accessible via GenBank (accession numbers MG014710MG014719) and in the Supplemental Information.

\section{Data Availability}

The following information was supplied regarding data availability:

The raw data are provided in the Supplemental Files.

\section{Supplemental Information}

Supplemental information for this article can be found online at http://dx.doi.org/ 10.7717/peerj.4953\#supplemental-information.

\section{REFERENCES}

Adham I, Schlösser M, Engel W. 2004. Acrosin. In: Barrett A, Rawlings N, Woessner J, eds. Handbook of Proteolytic Enzymes. Amsterdam and San Diego: Elsevier Academic Press, 1562-1565.

Akaike H. 1974. A new look at the statistical model identification. IEEE Transactions on Automatic Control 19(6):716-723 DOI 10.1109/TAC.1974.1100705. 
Araujo AC, Souto-Padrón T, Souza Wde. 1993. Cytochemical localization of carbohydrate residues in microfilariae of Wuchereria bancrofti and Brugia malayi. Journal of Histochemistry \& Cytochemistry 41(4):571-578 DOI 10.1177/41.4.8450196.

Asea A. 2003. Chaperokine-induced signal transduction pathways. Exercise Immunology Review 9:25-33.

Astakhova NM, Perelygin AA, Zharkikh AA, Lear TL, Coleman SJ, MacLeod JN, Brinton MA. 2009. Characterization of equine and other vertebrate TLR3, TLR7, and TLR8 genes. Immunogenetics 61(7):529-539 DOI 10.1007/s00251-009-0381-z.

Aujla SJ, Chan YR, Zheng M, Fei M, Askew DJ, Pociask DA, Reinhart TA, McAllister F, Edeal J, Gaus K, Husain S, Kreindler JL, Dubin PJ, Pilewski JM, Myerburg MM, Mason CA, Iwakura Y, Kolls JK. 2008. IL-22 mediates mucosal host defense against gram-negative bacterial pneumonia. Nature Medicine 14(3):275-281 DOI 10.1038/nm1710.

Ayoub NA, McGowen MR, Clark C, Springer MS, Gatesy J. 2009. Evolution and phylogenetic utility of the melanocortin-1 receptor gene (MC1R) in Cetartiodactyla. Molecular Phylogenetics and Evolution 52(2):550-557 DOI 10.1016/j.ympev.2009.03.008.

Bäckhed F, Normark S, Schweda EKH, Oscarson S, Richter-Dahlfors A. 2003. Structural requirements for TLR4-mediated LPS signalling: a biological role for LPS modifications. Microbes and Infection 5(12):1057-1063 DOI 10.1016/S1286-4579(03)00207-7.

Bailey AL, Lauck M, Ghai RR, Nelson CW, Heimbruch K, Hughes AL, Goldberg TL, Kuhn JH, Jasinska AJ, Freimer NB, Apetrei C, O’Connor DH. 2016. Arteriviruses, pegiviruses, and lentiviruses are common among wild African monkeys. Journal of Virology 90(15):6724-6737 DOI 10.1128/jvi.00573-16.

Bailey AL, Lauck M, Sibley SD, Pecotte J, Rice K, Weny G, Tumukunde A, Hyeroba D, Greene J, Correll M, Gleicher M, Friedrich TC, Jahrling PB, Kuhn JH, Goldberg TL, Rogers J, O’Connor DH. 2014a. Two novel simian arteriviruses in captive and wild baboons (Papio spp.). Journal of Virology 88(22):13231-13239 DOI 10.1128/jvi.02203-14.

Bailey AL, Lauck M, Weiler A, Sibley SD, Dinis JM, Bergman Z, Nelson CW, Correll M, Gleicher M, Hyeroba D, Tumukunde A, Weny G, Chapman C, Kuhn JH, Hughes AL, Friedrich TC, Goldberg TL, O’Connor DH. 2014b. High genetic diversity and adaptive potential of two simian hemorrhagic fever viruses in a wild primate population. PLOS ONE 9(3):e90714 DOI 10.1371/journal.pone.0090714.

Balayan MS. 1992. Natural hosts of hepatitis A virus. Vaccine 10:S27-S31 DOI 10.1016/0264-410X(92)90537-T.

Batista RL, Rodrigues AdS, Nishi MY, Gomes NL, Faria JAD, Moraes DRd, Carvalho LR, Costa EMF, Domenice S, Mendonca BB. 2017. A recurrent synonymous mutation in the human androgen receptor gene causing complete androgen insensitivity syndrome. Journal of Steroid Biochemistry and Molecular Biology 174:14-16 DOI 10.1016/j.jsbmb.2017.07.020.

Biasini M, Bienert S, Waterhouse A, Arnold K, Studer G, Schmidt T, Kiefer F, Cassarino TG, Bertoni M, Bordoli L, Schwede T. 2014. SWISS-MODEL: modelling protein tertiary and quaternary structure using evolutionary information. Nucleic Acids Research 42(W1): W252-W258 DOI 10.1093/nar/gku340.

Borgeaud C, Alvino M, van Leeuwen K, Townsend SW, Bshary R. 2015. Age/sex differences in third-party rank relationship knowledge in wild vervet monkeys, Chlorocebus aethiops pygerythrus. Animal Behaviour 102:277-284 DOI 10.1016/j.anbehav.2015.02.006.

Botting J, Whiten A, Grampp M, van de Waal E. 2018. Field experiments with wild primates reveal no consistent dominance-based bias in social learning. Animal Behaviour 136:1-12 DOI 10.1016/j.anbehav.2017.11.025. 
Brandtzaeg P. 2006. Pathogenesis and pathophysiology of invasive meningococcal disease. In: Frosch M, Maiden MCJ, eds. Handbook of Meningococcal Disease: Infection Biology, Vaccination, Clinical Management. Weinheim: Wiley-VCH, 427-480.

Chamary J, Hurst LD. 2005. Evidence for selection on synonymous mutations affecting stability of mRNA secondary structure in mammals. Genome biology 6:1.

Chamary J, Parmley JL, Hurst LD. 2006. Hearing silence: non-neutral evolution at synonymous sites in mammals. Nature Reviews Genetics 7(2):98-108 DOI 10.1038/nrg1770.

Chapman CA, Friant S, Godfrey K, Liu C, Sakar D, Schoof VA, Sengupta R, Twinomugisha D, Valenta K, Goldberg TL. 2016. Social behaviours and networks of vervet monkeys are influenced by gastrointestinal parasites. PLOS ONE 11(8):e0161113 DOI 10.1371/journal.pone.0161113.

Chapman CA, Speirs ML, Hodder SA, Rothman JM. 2010. Colobus monkey parasite infections in wet and dry habitats: implications for climate change. African Journal of Ecology 48(2):555-558 DOI 10.1111/j.1365-2028.2009.01123.x.

Chen S, Li K, Cao W, Wang J, Zhao T, Huan Q, Yang Y-F, Wu S, Qian W. 2017. Codon-resolution analysis reveals a direct and context-dependent impact of individual synonymous mutations on mRNA level. Molecular Biology and Evolution 34(11):2944-2958 DOI 10.1093/molbev/msx229.

Choudhuri S. 2014. Fundamentals of molecular evolution. In: Choudhuri S, ed. Bioinformatics for Beginners: Genes, Genomes, Molecular Evolution, Databases and Analytical Tools. Oxford: Academic Press, 27-53.

Darriba D, Taboada GL, Doallo R, Posada D. 2012. jModelTest 2: more models, new heuristics and parallel computing. Nature Methods 9(8):772 DOI 10.1038/nmeth.2109.

Diebold SS, Kaisho T, Hemmi H, Akira S, Reis e Sousa C. 2004. Innate antiviral responses by means of TLR7-mediated recognition of single-stranded RNA. Science 303(5663):1529-1531 DOI 10.1126/science.1093616.

Diebold SS, Massacrier C, Akira S, Paturel C, Morel Y, Reis e Sousa C. 2006. Nucleic acid agonists for Toll-like receptor 7 are defined by the presence of uridine ribonucleotides. European Journal of Immunology 36(12):3256-3267 DOI 10.1002/eji.200636617.

Duan J, Wainwright MS, Comeron JM, Saitou N, Sanders AR, Gelernter J, Gejman PV. 2003. Synonymous mutations in the human dopamine receptor D2 (DRD2) affect mRNA stability and synthesis of the receptor. Human Molecular Genetics 12(3):205-216 DOI 10.1093/hmg/12.3.205.

Dunn RR, Davies TJ, Harris NC, Gavin MC. 2010. Global drivers of human pathogen richness and prevalence. Proceedings of the Royal Society B: Biological Sciences 277(1694):2587-2595 DOI 10.1098/rspb.2010.0340.

Enard D, Cai L, Gwennap C, Petrov DA. 2016. Viruses are a dominant driver of protein adaptation in mammals. eLife 5:e12469 DOI 10.7554/elife.12469.

Excoffier L, Lischer HEL. 2010. Arlequin suite ver 3.5: a new series of programs to perform population genetics analyses under Linux and Windows. Molecular Ecology Resources 10(3):564-567 DOI 10.1111/j.1755-0998.2010.02847.x.

Fay JC, Wyckoff GJ, Wu C-I. 2001. Positive and negative selection on the human genome. Genetics 158:1227-1234.

Fornůsková A, Vinkler M, Pagès M, Galan M, Jousselin E, Cerqueira F, Morand S, Charbonnel N, Bryja J, Cosson J-F. 2013. Contrasted evolutionary histories of two Toll-like receptors (Tlr4 and Tlr7) in wild rodents (Murinae). BMC Evolutionary Biology 13(1):194

DOI 10.1186/1471-2148-13-194. 
Funk WC, McKay JK, Hohenlohe PA, Allendorf FW. 2012. Harnessing genomics for delineating conservation units. Trends in Ecology \& Evolution 27(9):489-496 DOI 10.1016/j.tree.2012.05.012.

Gaetano TJ, Danzy J, Mtshali MS, Theron N, Schmitt CA, Grobler JP, Freimer N, Turner TR. 2014. Mapping correlates of parasitism in wild South African vervet monkeys (Chlorocebus aethiops). South African Journal of Wildlife Research 44(1):56-70 DOI 10.3957/056.044.0105.

Gatesy J, Swanson WJ. 2007. Adaptive evolution and phylogenetic utility of Acr (acrosin), a rapidly evolving mammalian fertilization gene. Journal of Mammalogy 88(1):32-42 DOI 10.1644/05-mamm-s-345r1.1.

Goldman N, Yang Z. 1994. A codon-based model of nucleotide substitution for protein-coding DNA sequences. Molecular Biology and Evolution 11(5):725-736 DOI 10.1093/oxfordjournals.molbev.a040153.

Golubchik T, Wise MJ, Easteal S, Jermiin LS. 2007. Mind the gaps: evidence of bias in estimates of multiple sequence alignments. Molecular Biology and Evolution 24(11):2433-2442 DOI $10.1093 / \mathrm{molbev} / \mathrm{msm} 176$.

Gonzalez-Quevedo C, Spurgin LG, Illera JC, Richardson DS. 2015. Drift, not selection, shapes toll-like receptor variation among oceanic island populations. Molecular Ecology 24(23):5852-5863 DOI 10.1111/mec.13437.

Grueber CE, Wallis GP, Jamieson IG. 2014. Episodic positive selection in the evolution of avian Toll-like receptor innate immunity genes. PLOS ONE 9(3):e89632 DOI 10.1371/journal.pone.0089632.

Guernier V, Hochberg ME, Guégan J-F. 2004. Ecology drives the worldwide distribution of human diseases. PLOS Biology 2(6):e141 DOI 10.1371/journal.pbio.0020141.

Guex N, Peitsch MC. 1997. SWISS-MODEL and the Swiss-Pdb Viewer: an environment for comparative protein modeling. Electrophoresis 18(15):2714-2723 DOI 10.1002/elps.1150181505.

Hamilton WD. 1982. Pathogens as Causes of Genetic Diversity in their Host Populations. Berlin, Heidelberg: Springer Berlin Heidelberg, 269-296.

Hammer Ø, Harper DAT, Ryan PD. 2001. PAST: paleontological statistics software package for education and data analysis. Palaeontologia Electronica 4:9.

Hartmann SA, Schaefer HM, Segelbacher G. 2014. Genetic depletion at adaptive but not neutral loci in an endangered bird species. Molecular Ecology 23(23):5712-5725 DOI 10.1111/mec.12975.

Harvell D, Altizer S, Cattadori IM, Harrington L, Weil E. 2009. Climate change and wildlife diseases: when does the host matter the most? Ecology 90(4):912-920 DOI 10.1890/08-0616.1.

Heil F, Hemmi H, Hochrein H, Ampenberger F, Kirschning C, Akira S, Lipford G, Wagner H, Bauer S. 2004. Species-specific recognition of single-stranded RNA via toll-like receptor 7 and 8. Science 303(5663):1526-1529 DOI 10.1126/science.1093620.

Hemmi H, Takeuchi O, Kawai T, Kaisho T, Sato S, Sanjo H, Matsumoto M, Hoshino K, Wagner H, Takeda K, Akira S. 2000. A Toll-like receptor recognizes bacterial DNA. Nature 408(6813):740-745 DOI 10.1038/35047123.

Hoffmann M, Hilton-Taylor C. 2008. Papio ursinus (errata version published in 2016). The IUCN Red List of Threatened Species 2008:e.T16022A99710253 DOI 10.2305/IUCN.UK.2008.RLTS.T16022A5356469.en.

Holderegger R, Kamm U, Gugerli F. 2006. Adaptive vs. neutral genetic diversity: implications for landscape genetics. Landscape Ecology 21(6):797-807 DOI 10.1007/s10980-005-5245-9. 
Hunt RC, Simhadri VL, Iandoli M, Sauna ZE, Kimchi-Sarfaty C. 2014. Exposing synonymous mutations. Trends in Genetics 30(7):308-321 DOI 10.1016/j.tig.2014.04.006.

Hurst LD, Smith NGC. 1999. Do essential genes evolve slowly? Current Biology 9(14):747-750 DOI 10.1016/S0960-9822(99)80334-0.

HyPhy. 2018. Methods for inferring selection pressure. Available at http://hyphy.org/methods/ selection-methods/\#fel (accessed 3 April 2018).

Janssens S, Beyaert R. 2003. Role of Toll-like receptors in pathogen recognition. Clinical Microbiology Reviews 16(4):637-646 DOI 10.1128/cmr.16.4.637-646.2003.

Katoh K, Misawa K, Kuma Ki, Miyata T. 2002. MAFFT: a novel method for rapid multiple sequence alignment based on fast Fourier transform. Nucleic Acids Research 30(14):3059-3066 DOI 10.1093/nar/gkf436.

Katoh K, Rozewicki J, Yamada KD. 2017. MAFFT online service: multiple sequence alignment, interactive sequence choice and visualization. Epub ahead of print 6 September 2017. Briefings in Bioinformatics DOI 10.1093/bib/bbx108.

Kaup F-J, Bruno S, Mätz-Rensing K, Schneider T. 2005. Tubuloreticular structures in rectal biopsies of SIV-infected rhesus monkeys (Macaca mulatta). Ultrastructural Pathology 29(5):357-366 DOI 10.1080/019131290968740.

Kearse M, Moir R, Wilson A, Stones-Havas S, Cheung M, Sturrock S, Buxton S, Cooper A, Markowitz S, Duran C, Thierer T, Ashton B, Meintjes P, Drummond A. 2012. Geneious Basic: an integrated and extendable desktop software platform for the organization and analysis of sequence data. Bioinformatics 28(12):1647-1649 DOI 10.1093/bioinformatics/bts199.

Keime S, Adham IM, Engel W. 1990. Nucleotide sequence and exon-intron organization of the human proacrosin gene. European Journal of Biochemistry 190(1):195-200 DOI 10.1111/j.1432-1033.1990.tb15564.x.

Kilár A, Dörnyei Á, Kocsis B. 2013. Structural characterization of bacterial lipopolysaccharides with mass spectrometry and on- and off-line separation techniques. Mass Spectrometry Reviews 32(2):90-117 DOI 10.1002/mas.21352.

Kingdon J, Gippoliti S, Butynski TM, de Jong Y. 2008. Chlorocebus pygerythrus. The IUCN red list of threatened species. Version 2015.2. Available at www.iucnredlist.org.

Kohlhase M. 2006. CodeML: an open markup format the content and presentatation of program code. Computer Science, Carnegie Mellon University Pittsburgh. Available at https://svn.omdoc. org/repos/codeml/doc/spec/codeml.pdf.

Kosakovsky Pond SL, Frost SDW. 2005. Datamonkey: rapid detection of selective pressure on individual sites of codon alignments. Bioinformatics 21(10):2531-2533 DOI 10.1093/bioinformatics/bti320.

Kupek E, de Sousa SFM, de Souza PJ. 2000. The relationship between rainfall and human leptospirosis in Florianópolis, Brazil, 1991-1996. Brazilian Journal of Infectious Diseases 4:131-134.

Kurt-Jones EA, Popova L, Kwinn L, Haynes LM, Jones LP, Tripp RA, Walsh EE, Freeman MW, Golenbock DT, Anderson LJ, Finberg RW. 2000. Pattern recognition receptors TLR4 and CD14 mediate response to respiratory syncytial virus. Nature Immunology 1(5):398-401 DOI $10.1038 / 80833$.

Lafferty KD. 2009. The ecology of climate change and infectious diseases. Ecology 90(4):888-900 DOI 10.1890/08-0079.1.

Lee CG, Da Silva CA, Lee J-Y, Hartl D, Elias JA. 2008. Chitin regulation of immune responses: an old molecule with new roles. Current Opinion in Immunology 20(6):684-689

DOI 10.1016/j.coi.2008.10.002. 
Lee JY, Sohn KH, Rhee SH, Hwang D. 2001. Saturated fatty acids, but not unsaturated fatty acids, induce the expression of cyclooxygenase-2 mediated through Toll-like receptor 4. Journal of Biological Chemistry 276(20):16683-16689 DOI 10.1074/jbc.m011695200.

Lee J, Wu CCN, Lee KJ, Chuang T-H, Katakura K, Liu Y-T, Chan M, Tawatao R, Chung M, Shen C, Cottam HB, Lai MMC, Raz E, Carson DA. 2006. Activation of anti-hepatitis $C$ virus responses via Toll-like receptor 7. Proceedings of the National Academy of Sciences of the United States of America 103(6):1828-1833 DOI 10.1073/pnas.0510801103.

Leigh JW, Bryant D. 2015. Popart: full-feature software for haplotype network construction. Methods in Ecology and Evolution 6(9):1110-1116 DOI 10.1111/2041-210X.12410.

Librado P, Rozas J. 2009. DnaSP v5: a software for comprehensive analysis of DNA polymorphism data. Bioinformatics 25(11):1451-1452 DOI 10.1093/bioinformatics/btp187.

Little T. 2002. The evolutionary significance of parasitism: do parasite-driven genetic dynamics occur ex silico? Journal of Evolutionary Biology 15(1):1-9 DOI 10.1046/j.1420-9101.2002.00366.x.

Lovegrove BG. 2003. The influence of climate on the basal metabolic rate of small mammals: a slow-fast metabolic continuum. Journal of Comparative Physiology B 173:87-112

DOI 10.1007/s00360-002-0309-5.

Lund JM, Alexopoulou L, Sato A, Karow M, Adams NC, Gale NW, Iwasaki A, Flavell RA. 2004. Recognition of single-stranded RNA viruses by Toll-like receptor 7. Proceedings of the National Academy of Sciences of the United States of America 101(15):5598-5603 DOI 10.1073/pnas.0400937101.

Lund J, Sato A, Akira S, Medzhitov R, Iwasaki A. 2003. Toll-like receptor 9-mediated recognition of herpes simplex virus-2 by plasmacytoid dendritic cells. Journal of Experimental Medicine 198(3):513-520 DOI 10.1084/jem.20030162.

Ma D, Jasinska A, Kristoff J, Grobler JP, Turner T, Jung Y, Schmitt C, Raehtz K, Feyertag F, Martinez Sosa N, Wijewardana V, Burke DS, Robertson DL, Tracy R, Pandrea I, Freimer N, Apetrei C, The International Vervet Research Consortium. 2013. SIVagm infection in wild African green monkeys from South Africa: epidemiology, natural history, and evolutionary considerations. PLOS Pathogens 9(1):e1003011 DOI 10.1371/journal.ppat.1003011.

Maldonado E, Sunagar K, Almeida D, Vasconcelos V, Antunes A. 2014. IMPACT_S: integrated multiprogram platform to analyze and combine tests of selection. PLOS ONE 9(10):e96243 DOI 10.1371/journal.pone.0096243.

Mancuso G, Gambuzza M, Midiri A, Biondo C, Papasergi S, Akira S, Teti G, Beninati C. 2009. Bacterial recognition by TLR7 in the lysosomes of conventional dendritic cells. Nature Immunology 10(6):587-594 DOI 10.1038/ni.1733.

Manning SD. 2010. Escherichia coli Infections. New York: Infobase Publishing.

Mendell AL, Szigeti-Buck K, MacLusky NJ, Leranth C. 2014. Orchidectomy does not significantly affect spine synapse density in the CA3 hippocampal subfield in St. Kitts vervet monkeys (Chlorocebus aethiops sabaeus). Neuroscience Letters 559:189-192

DOI 10.1016/j.neulet.2013.10.061.

Metz EC, Robles-Sikisaka R, Vacquier VD. 1998. Nonsynonymous substitution in abalone sperm fertilization genes exceeds substitution in introns and mitochondrial DNA. Proceedings of the National Academy of Sciences of the United States of America 95(18):10676-10681 DOI 10.1073/pnas.95.18.10676.

Mucina L, Rutherford MC. 2006. The Vegetation of South Africa, Lesotho and Swaziland. Pretoria: South African National Biodiversity Institute. 
Murray C, Huerta-Sanchez E, Casey F, Bradley DG. 2010. Cattle demographic history modelled from autosomal sequence variation. Philosophical Transactions of the Royal Society B 365(1552):2531-2539 DOI 10.1098/rstb.2010.0103.

Murrell B, Moola S, Mabona A, Weighill T, Sheward D, Kosakovsky Pond SL, Scheffler K. 2013. FUBAR: a fast, unconstrained Bayesian AppRoximation for inferring selection. Molecular Biology and Evolution 30(5):1196-1205 DOI 10.1093/molbev/mst030.

Murrell B, Wertheim JO, Moola S, Weighill T, Scheffler K, Kosakovsky Pond SL. 2012. Detecting individual sites subject to episodic diversifying selection. PLOS Genetics 8(7):e1002764 DOI 10.1371/journal.pgen.1002764.

Nakajima T, Ohtani H, Satta Y, Uno Y, Akari H, Ishida T, Kimura A. 2008. Natural selection in the TLR-related genes in the course of primate evolution. Immunogenetics 60(12):727-735 DOI 10.1007/s00251-008-0332-0.

Ohashi K, Burkart V, Flohé S, Kolb H. 2000. Cutting edge: heat shock protein 60 is a putative endogenous ligand of the toll-like receptor-4 complex. Journal of Immunology 164(2):558-561 DOI 10.4049/jimmunol.164.2.558.

Ohto U, Yamakawa N, Akashi-Takamura S, Miyake K, Shimizu T. 2012. Structural analyses of human Toll-like receptor 4 polymorphisms D299G and T399I. Journal of Biological Chemistry 287(48):40611-40617 DOI 10.1074/jbc.M112.404608.

Pagani F, Raponi M, Baralle FE. 2005. Synonymous mutations in CFTR exon 12 affect splicing and are not neutral in evolution. Proceedings of the National Academy of Sciences of the United States of America 102(18):6368-6372 DOI 10.1073/pnas.0502288102.

Parmley JL, Chamary JV, Hurst LD. 2006. Evidence for purifying selection against synonymous mutations in mammalian exonic splicing enhancers. Molecular Biology and Evolution 23(2):301-309 DOI 10.1093/molbev/msj035.

Patz JA, Epstein PR, Burke TA, Balbus JM. 1996. Global climate change and emerging infectious diseases. Journal of the American Medical Association 275(3):217-223 DOI 10.1001/jama.275.3.217.

Poltorak A, Ricciardi-Castagnoli P, Citterio S, Beutler B. 2000. Physical contact between lipopolysaccharide and toll-like receptor 4 revealed by genetic complementation. Proceedings of the National Academy of Sciences of the United States of America 97(5):2163-2167 DOI 10.1073/pnas.040565397.

Quéméré E, Galan M, Cosson JF, Klein F, Aulagnier S, Gilot-Fromont E, Merlet J, Bonhomme M, Hewison A, Charbonnel N. 2015. Immunogenetic heterogeneity in a widespread ungulate: the European roe deer (Capreolus capreolus). Molecular Ecology 24:3873-3887.

Raetz CR, Ulevitch RJ, Wright SD, Sibley CH, Ding A, Nathan CF. 1991. Gram-negative endotoxin: an extraordinary lipid with profound effects on eukaryotic signal transduction. FASEB Journal 5(12):2652-2660 DOI 10.1096/fasebj.5.12.1916089.

Raterman D, Springer MS. 2008. The molecular evolution of acrosin in placental mammals. Molecular Reproduction and Development 75(7):1196-1207 DOI 10.1002/mrd.20868.

Ribeiro AA, Zhou Z, Raetz CRH. 1999. Multi-dimensional NMR structural analyses of purified Lipid X and Lipid A (endotoxin). Magnetic Resonance in Chemistry 37(9):620-630 DOI 10.1002/(SICI)1097-458X(199909)37:9<620::AID-MRC517>3.0.CO;2-Q.

Roach JC, Glusman G, Rowen L, Kaur A, Purcell MK, Smith KD, Hood LE, Aderem A. 2005. The evolution of vertebrate Toll-like receptors. Proceedings of the National Academy of Sciences of the United States of America 102:9577-9582. 
Rodríguez RL, Cramer JD, Schmitt CA, Gaetano TJ, Grobler JP, Freimer NB, Turner TR. 2015. The static allometry of sexual and nonsexual traits in vervet monkeys. Biological Journal of the Linnean Society 114(3):527-537 DOI 10.1111/bij.12440.

Roelofs MF, Boelens WC, Joosten LAB, Abdollahi-Roodsaz S, Geurts J, Wunderink LU, Schreurs BW, van den Berg WB, Radstake TRDJ. 2006. Identification of small heat shock protein B8 (HSP22) as a novel TLR4 ligand and potential involvement in the pathogenesis of rheumatoid arthritis. Journal of Immunology 176(11):7021-7027

DOI 10.4049/jimmunol.176.11.7021.

Rozen S, Skaletsky H. 1999. Primer3 on the WWW for general users and for biologist programmers. In: Misener S, Krawetz SA, eds. Bioinformatics Methods and Protocols. Totowa: Humana Press, 365-386.

Sbisà E, Tanzariello F, Reyes A, Pesole G, Saccone C. 1997. Mammalian mitochondrial D-loop region structural analysis: identification of new conserved sequences and their functional and evolutionary implications. Gene 205(1-2):125-140 DOI 10.1016/s0378-1119(97)00404-6.

Sibly RM, Brown JH. 2007. Effects of body size and lifestyle on evolution of mammal life histories. Proceedings of the National Academy of Sciences of the United States of America 104(45):17707-17712 DOI 10.1073/pnas.0707725104.

Sibly RM, Brown JH. 2009. Mammal reproductive strategies driven by offspring mortality-size relationships. American Naturalist 173(6):E185-E199 DOI 10.1086/598680.

Sicard J-F, Le Bihan G, Vogeleer P, Jacques M, Harel J. 2017. Interactions of intestinal bacteria with components of the intestinal mucus. Frontiers in Cellular and Infection Microbiology 7:387 DOI 10.3389/fcimb.2017.00387.

Simmons RP, Scully EP, Groden EE, Benedict KF, Chang JJ, Lane K, Lifson J, Rosenberg E, Lauffenburger DA, Altfeld M. 2013. HIV-1 infection induces strong production of IP-10 through TLR7/9-dependent pathways. AIDS 27(16):2505-2517

DOI 10.1097/01.aids.0000432455.06476.bc.

Skinner JD, Chimimba CT. 2005. The Mammals of the Southern African Sub-Region. Third Edition. Cape Town: Cambridge University Press.

Stephens M, Scheet P. 2005. Accounting for decay of linkage disequilibrium in haplotype inference and missing-data imputation. American Journal of Human Genetics 76(3):449-462 DOI 10.1086/428594.

Stephens M, Smith NJ, Donnelly P. 2001. A new statistical method for haplotype reconstruction from population data. American Journal of Human Genetics 68(4):978-989

DOI 10.1086/319501.

Svardal H, Jasinska AJ, Apetrei C, Coppola G, Huang Y, Schmitt CA, Jacquelin B, Ramensky V, Müller-Trutwin M, Antonio M, Weinstock G, Grobler JP, Dewar K, Wilson RK, Turner TR, Warren WC, Freimer NB, Nordborg M. 2017. Ancient hybridization and strong adaptation to viruses across African vervet monkey populations. Nature Genetics 49(12):1705-1713 DOI 10.1038/ng.3980.

Swanson WJ, Nielsen R, Yang Q. 2003. Pervasive adaptive evolution in mammalian fertilization proteins. Molecular Biology and Evolution 20(1):18-20 DOI 10.1093/oxfordjournals.molbev.a004233.

Swanson WJ, Yang Z, Wolfner MF, Aquadro CF. 2001. Positive Darwinian selection drives the evolution of several female reproductive proteins in mammals. Proceedings of the National Academy of Sciences of the United States of America 98(5):2509-2514 DOI 10.1073/pnas.051605998.

Takeda K, Kaisho T, Akira S. 2003. Toll-like receptors. Annual Review of Immunology 21(1):335-376 DOI 10.1146/annurev.immunol.21.120601.141126. 
Takeuchi O, Hoshino K, Kawai T, Sanjo H, Takada H, Ogawa T, Takeda K, Akira S. 1999. Differential roles of TLR2 and TLR4 in recognition of gram-negative and gram-positive bacterial cell wall components. Immunity 11(4):443-451 DOI 10.1016/S1074-7613(00)80119-3.

Thompson JD, Higgins DG, Gibson TJ. 1994. CLUSTAL W: improving the sensitivity of progressive multiple sequence alignment through sequence weighting, position-specific gap penalties and weight matrix choice. Nucleic Acids Research 22(22):4673-4680 DOI 10.1093/nar/22.22.4673.

Tranter R, Read JA, Jones R, Brady RL. 2000. Effector sites in the three-dimensional structure of mammalian sperm $\beta$-Acrosin. Structure 8(11):1179-1188 DOI 10.1016/S0969-2126(00)00523-2.

Tschirren B, Andersson M, Scherman K, Westerdahl H, Råberg L. 2012. Contrasting patterns of diversity and population differentiation at the innate immunity gene Toll-like receptor 2 (TLR2) in two sympatric rodent species. Evolution 66(3):720-731 DOI 10.1111/j.1558-5646.2011.01473.x.

Turner T, Hill R, Coetzer W, Patterson L. 2016a. A Conservation Assessment of Chlorocebus pygerythrus. South Africa: South African National Biodiversity Institute and Endangered Wildlife Trust.

Turner TR, Coetzer WG, Schmitt CA, Lorenz JG, Freimer NB, Grobler JP. 2016b. Localized population divergence of vervet monkeys (Chlorocebus spp.) in South Africa: evidence from mtDNA. American Journal of Physical Anthropology 159(1):17-30 DOI 10.1002/ajpa.22825.

Twenhafel N, Whitehouse C, Stevens E, Hottel H, Foster C, Gamble S, Abbott S, Janda J, Kreiselmeier N, Steele K. 2008. Multisystemic abscesses in African green monkeys (Chlorocebus aethiops) with invasive Klebsiella pneumoniae-identification of the hypermucoviscosity phenotype. Veterinary Pathology 45(2):226-231 DOI 10.1354/vp.45-2-226.

Tzeng Y-L, Datta A, Kolli VK, Carlson RW, Stephens DS. 2002. Endotoxin of Neisseria meningitidis composed only of intact lipid A: inactivation of the meningococcal 3-deoxy-D-manno-octulosonic acid transferase. Journal of Bacteriology 184(9):2379-2388 DOI 10.1128/jb.184.9.2379-2388.2002.

Vasemägi A, Primmer C. 2005. Challenges for identifying functionally important genetic variation: the promise of combining complementary research strategies. Molecular Ecology 14(12):3623-3642 DOI 10.1111/j.1365-294x.2005.02690.x.

Veness C. 2017. Calculate distance, bearing and more between Latitude/Longitude points. Available at http://www.movable-type.co.uk/scripts/latlong.html (accessed 25 July 2017).

Villaseñor-Cardoso MI, Ortega E. 2011. Polymorphisms of innate immunity receptors in infection by parasites. Parasite Immunology 33(12):643-653

DOI 10.1111/j.1365-3024.2011.01327.x.

Vinkler M, Albrecht T. 2009. The question waiting to be asked: innate immunity receptors in the perspective of zoological research. Folia Zoologica 58:15-28.

Wang JP, Bowen GN, Padden C, Cerny A, Finberg RW, Newburger PE, Kurt-Jones EA. 2008. Toll-like receptor-mediated activation of neutrophils by influenza A virus. Blood 112(5):2028-2034 DOI 10.1182/blood-2008-01-132860.

Webster RG, Bean WJ, Gorman OT, Chambers TM, Kawaoka Y. 1992. Evolution and ecology of influenza A viruses. Microbiological Reviews 56:152-179.

Wilson AC, Cann RL, Carr SM, George M, Gyllensten UB, Helm-Bychowski KM, Higuchi RG, Palumbi SR, Prager EM, Sage RD, Stoneking M. 1985. Mitochondrial DNA and two perspectives on evolutionary genetics. Biological Journal of the Linnean Society 26(4):375-400 DOI 10.1111/j.1095-8312.1985.tb02048.x. 
Wimberger K, Downs C, Boyes R. 2010. A survey of wildlife rehabilitation in South Africa: is there a need for improved management? Animal Welfare 19:481.

Wlasiuk G, Nachman MW. 2010. Adaptation and constraint at Toll-like receptors in primates. Molecular Biology and Evolution 27(9):2172-2186 DOI 10.1093/molbev/msq104.

Woods RP, Fears SC, Jorgensen MJ, Fairbanks LA, Toga AW, Freimer NB. 2011. A web-based brain atlas of the vervet monkey, Chlorocebus aethiops. NeuroImage 54(3):1872-1880 DOI 10.1016/j.neuroimage.2010.09.070.

Wren BT, Gillespie TR, Camp JW, Remis MJ. 2015. Helminths of vervet monkeys, Chlorocebus aethiops, from Loskop Dam Nature Reserve, South Africa. Comparative Parasitology 82(1):101-108 DOI 10.1654/4712rr.1.

Xu B, Yang Z. 2013. PAMLX: a graphical user interface for PAML. Molecular Biology and Evolution 30(12):2723-2724 DOI 10.1093/molbev/mst179.

Yang Z. 2007. PAML 4: phylogenetic analysis by maximum likelihood. Molecular Biology and Evolution 24(8):1586-1591 DOI 10.1093/molbev/msm088.

Yang Z, Nielsen R, Goldman N, Pedersen AM. 2000. Codon-substitution models for heterogeneous selection pressure at amino acid sites. Genetics 155(1):431-449.

Yang Z, Wong WS, Nielsen R. 2005. Bayes empirical Bayes inference of amino acid sites under positive selection. Molecular Biology and Evolution 22(4):1107-1118 DOI 10.1093/molbev/msi097.

Zhan J, Mundt CC, Hoffer M, McDonald BA. 2002. Local adaptation and effect of host genotype on the rate of pathogen evolution: an experimental test in a plant pathosystem. Journal of Evolutionary Biology 15(4):634-647 DOI 10.1046/j.1420-9101.2002.00428.x.

Zhang Z, Huang L, Shulmeister VM, Chi Y-I, Kim KK, Hung L-W, Crofts AR, Berry EA, Kim S-H. 1998. Electron transfer by domain movement in cytochrome bc 1. Nature 392:677.

Zhang Z, Ohto U, Shibata T, Krayukhina E, Taoka M, Yamauchi Y, Tanji H, Isobe T, Uchiyama S, Miyake K, Shimizu T. 2016. Structural analysis reveals that Toll-like receptor 7 is a dual receptor for guanosine and single-stranded RNA. Immunity 45(4):737-748

DOI 10.1016/j.immuni.2016.09.011. 